\title{
Exogenous Hydrogen Sulfide Supplement Attenuates Isoproterenol-Induced Myocardial Hypertrophy in a Sirtuin 3-Dependent Manner
}

\author{
Jingyao Zhang, ${ }^{1}$ Jin Yu, ${ }^{1,2}$ Yun Chen, ${ }^{1}$ Lulu Liu, ${ }^{1}$ Mengting Xu, ${ }^{1}$ Linlin Sun, ${ }^{1}$ Huiqin Luo, ${ }^{1}$ \\ Yuqin Wang, and Guoliang Meng $\mathbb{D i D}^{1}$ \\ ${ }^{1}$ Department of Pharmacology, School of Pharmacy, Nantong University, Key Laboratory of Inflammation and Molecular Drug \\ Target of Jiangsu Province, Nantong, 226001 Jiangsu, China \\ ${ }^{2}$ Department of Pharmacology, Yancheng City No. 1 People’s Hospital, Yancheng, 224001 Jiangsu, China
}

Correspondence should be addressed to Guoliang Meng; mengguoliang@ntu.edu.cn

Received 16 April 2018; Accepted 11 October 2018; Published 17 December 2018

Academic Editor: Przemko Tylzanowski

Copyright ( 2018 Jingyao Zhang et al. This is an open access article distributed under the Creative Commons Attribution License, which permits unrestricted use, distribution, and reproduction in any medium, provided the original work is properly cited.

\begin{abstract}
Hydrogen sulfide $\left(\mathrm{H}_{2} \mathrm{~S}\right)$ is a gasotransmitter with a variety of cardiovascular protective effects. Sirtuin 3 (SIRT3) is closely related to mitochondrial function and oxidative stress. We found that NaHS increased SIRT3 expression in the preventive effect on isoproterenol- (ISO-) induced myocardial hypertrophy. We further investigated whether exogenous $\mathrm{H}_{2} \mathrm{~S}$ supplement improved ISO-induced myocardial hypertrophy in a SIRT3-dependent manner. 10-week-old male 129S1/SvImJ (WT) mice and SIRT3 knockout (KO) mice were intraperitoneally injected with NaHS $(50 \mu \mathrm{mol} / \mathrm{kg} / \mathrm{d})$ for two weeks and then intraperitoneally injected with ISO $(60 \mathrm{mg} / \mathrm{kg} / \mathrm{d})$ for another two weeks. In WT mice, NaHS significantly reduced the cardiac index of ISOinduced mice, decreased the cross-sectional area of cardiomyocytes, and inhibited the expressions of atrial natriuretic peptide (ANP) and brain natriuretic peptide (BNP) mRNA. The activity of total antioxidant capacity (T-AOC) and superoxide dismutase (SOD) in the myocardium was increased, but the level of malondialdehyde (MDA) was decreased. The fluorescence intensity of dihydroethidium staining for superoxide anion was attenuated. Optic atrophy 1 (OPA1) expression was upregulated, while dynamin-related protein 1 (DRP1) expression was downregulated. ERK, but not P38 and JNK, phosphorylation was downregulated. However, all above protective effects were unavailable in ISO-induced SIRT3 KO mice. Our present study suggested that exogenous $\mathrm{H}_{2} \mathrm{~S}$ supplement inhibited ISO-induced cardiac hypertrophy depending on SIRT3, which might be associated with antioxidant stress.
\end{abstract}

\section{Introduction}

Myocardial hypertrophy is a compensatory process with increased cardiac mass and myocardial contractility under a long-term pressure overload, which is beneficial to maintaining normal blood circulation [1]. However, there is no adequate coronary artery blood to meet the needs of the heart because hypertrophic myocardium requires more oxygen. It is easy to result in myocardial ischemia, myocardial contractility impairment, and eventually heart failure if the heart suffers from persistent pathological hypertrophy [2]. Multilevel and complex factors, such as oxidative stress, energy metabolism disorder, hemodynamic factors, neurohumoral factors, cardiovascular autocrine/paracrine factors, insulin resistance, microRNAs, and genetics, are involved in the progress of myocardial hypertrophy [3-9]. Until now, the exact molecular mechanism for myocardial hypertrophy is still incompletely clarified. It is important to find novel compounds to delay or reverse myocardial hypertrophy.

In the traditional concept, hydrogen sulfide $\left(\mathrm{H}_{2} \mathrm{~S}\right)$ is a gas with highly toxic, which damages physiological functions [10]. A small amount of high concentration of $\mathrm{H}_{2} \mathrm{~S}$ might achieve a fatal effect in a short time after inhalation [11]. But with the deepening understanding of $\mathrm{H}_{2} \mathrm{~S}$ in recent years, it has revealed that $\mathrm{H}_{2} \mathrm{~S}$ has important physiological functions in the nervous system, the immune system, the 
digestive system, and so on [12-17]. $\mathrm{H}_{2} \mathrm{~S}$ widely exists in many mammals and is widely concerned as the third gasotransmitter followed by nitric oxide and carbon monoxide [18]. $\mathrm{H}_{2} \mathrm{~S}$ is mainly produced by three enzymes: cystathionine $\gamma$-lyase (CSE), cystathionine $\beta$-synthase (CBS), and 3-mercaptopyruvate sulfurtransferase (MPST) [19].

Our previous studies found that $\mathrm{H}_{2} \mathrm{~S}$ decreased blood pressure in spontaneously hypertensive rats (SHR) [20] and transverse aortic constricted mice [21], inhibited myocardial fibrosis in SHR [22], improved vascular endothelial function [23], and prevented diabetic atherosclerosis [24]. It suggested that $\mathrm{H}_{2} \mathrm{~S}$ played an important role in cardiovascular system. However, the mechanisms of $\mathrm{H}_{2} \mathrm{~S}$ on cardiac hypertrophy were not completely clear. Glucose-6-phosphate dehydrogenase [25], miR-133a upregulation [26], nuclear factor E2related factor 2 (Nrf2) activation [27], and specific protein 1 S-sulfhydration [20] were previously thought to be the principal reasons for the protective effect of $\mathrm{H}_{2} \mathrm{~S}$ on myocardial hypertrophy. These studies suggested that the detailed mechanisms for the effects of $\mathrm{H}_{2} \mathrm{~S}$ on myocardial hypertrophy in different models were not completely consistent. Therefore, it is vital to explore the specific mechanism of $\mathrm{H}_{2} \mathrm{~S}$ for delaying or reversing myocardial hypertrophy.

Sirtuin 3 (SIRT3) is a histone deacetylase which was encoded by the SIRT3 gene and localized in the mitochondria [28]. It is found that SIRT3 deficiency promoted cardiac fibrosis and left ventricular dilatation, which might even deteriorate to decompensated cardiac dysfunction in the aging mice [29]. In the rodent model of heart failure, SIRT3 expression and activity were decreased. Levels of mitochondrial protein lysine acetylation were increased, which might promote oxidative stress [30]. Impaired SIRT3 blocked fatty acid oxidation, glucose oxidation, tricarboxylic acid cycle, and oxidative phosphorylation, which might be a potential mechanism for contraction dysfunction and adaptation impairment [31-33]. Contrarily, SIRT3 protected the heart from reactive oxygen species- (ROS-) induced oxidative damage. Different pharmacological approaches to increase SIRT3 expression or to enhance SIRT3 activity were a potent strategy to attenuate myocardial hypertrophy and other cardiovascular diseases [34-38]. Our previous research also found that $\mathrm{H}_{2} \mathrm{~S}$ increased SIRT3 promoter activity and SIRT3 expression in angiotensin II-induced cardiomyocyte hypertrophy [21]. However, the detailed information about the potential role of SIRT3 on myocardial hypertrophy by $\mathrm{H}_{2} \mathrm{~S}$ in vivo was not known well.

As well as we know, dynamin-related protein 1 (DRP1) is a mitochondrial fission-associated protein, while optic atrophy 1 (OPA1) is a mitochondrial fusion-associated protein [39-42]. The balance of DRP1 and OPA1 plays an important role in maintaining mitochondrial structure and function. However, whether $\mathrm{H}_{2} \mathrm{~S}$ regulated DRP1 and OPA1 in the protective effect against myocardial hypertrophy was unknown.

The aims of the present study were to examine whether exogenous $\mathrm{H}_{2} \mathrm{~S}$ supplement attenuated isoproterenol- (ISO-) induced myocardial hypertrophy in SIRT3 knockout (KO) mice. It is beneficial to elucidate the possible role of SIRT3 in this protective effect of $\mathrm{H}_{2} \mathrm{~S}$.

\section{Materials and Methods}

2.1. Treatment of Animals. Male C57BL/6, 129S1/SvImJ (WT), and SIRT3 knockout (KO) mice at 10 weeks of age were randomly administrated with $\mathrm{NaHS}(50 \mu \mathrm{mol} / \mathrm{kg} / \mathrm{d}$; Sigma-Aldrich, St. Louis, MO, USA) or normal saline (NS) once daily. After 2 weeks, the mice were given isoproterenol (ISO, $60 \mathrm{mg} / \mathrm{kg}$; Sigma-Aldrich, St. Louis, MO, USA) by intraperitoneal injection to induce myocardial hypertrophy followed by NaHS or NS administration once daily for another 2 weeks [43].

Animal experiments were performed in accordance with the NIH guidelines for Care and Use of Laboratory Animals. The study was approved by the Committee on Animal Care of Nantong University (approval no. NTUERLAUA-20160115).

2.2. Measurement of Blood Pressure. After 2-week administration of ISO, systolic blood pressure (SBP), diastolic blood pressure (DBP), and mean arterial pressure (MAP) were detected from left carotid artery before sacrifice.

2.3. Echocardiography. After treatment, mice were anesthetized with isoflurane (1.5\%). Echocardiography was used to detect the heart configuration through parasternal long axis view using a small animal color ultrasonic diagnostic apparatus (Visual Sonic Vevo 2100) with $30 \mathrm{MHz}$ probe. Images were obtained by M-mode echocardiography. Thickness of inter ventricular septum (IVS) and left ventricular posterior wall (LVPW) was recorded. The average ejection fraction (EF) and left ventricular fraction shortening (FS) in 10 cycles were calculated.

2.4. Measure of $\mathrm{H}_{2} \mathrm{~S}$ Concentration in the Plasma and $\mathrm{H}_{2} \mathrm{~S}$ Production in the Myocardium. $\mathrm{H}_{2} \mathrm{~S}$ specific microelectrodes (World Precision Instruments) connected to the free radical analyzer (TBR4100, World Precision Instruments) were used to measure the concentration of $\mathrm{H}_{2} \mathrm{~S}$ in the plasma [23]. The sensor was depolarized before the experiment and then was calibrated with different concentration of $\mathrm{Na}_{2} \mathrm{~S}(0.5,1,2$, 4 , and $8 \mu \mathrm{mol} / \mathrm{L})$. The current increased after the plasma was added. According to the enhanced current and $\mathrm{Na}_{2} \mathrm{~S}$ concentration, the standard curve was drawn, and the concentration of $\mathrm{H}_{2} \mathrm{~S}$ in plasma was calculated.

Myocardial homogenate was prepared with potassium phosphate buffer (1/10, myocardial tissue weigh/buffer volume). After centrifugation, $\mathrm{H}_{2} \mathrm{~S}$ production in the myocardium was measured as previously described, which represented the activity of $\mathrm{H}_{2} \mathrm{~S}$ synthase enzymes [23]. CSE, CBS, and MPST mRNA expressions were measured by quantitative real-time PCR.

2.5. Measurement of Cardiac Index. After echocardiography, the hearts were collected. The heart weight (HW) and left ventricular weight (LVW) were measured. The heart mass index (HMI) and left ventricular mass index (LVMI) were normalized by body weight (BW). HMI was represented as the ratio of $\mathrm{HW}$ to $\mathrm{BW}$. LVMI was represented as the ratio of LVW to HW. The tibia length (TL) from the tibial plateau to medial malleolus of the right hindlimb was measured. The 
ratio of LVW to TL was calculated, which was proportional to heart mass.

2.6. Wheat Germ Agglutinin (WGA) Staining. Heart tissue sections were reconstituted with different concentrations of ethanol $(100 \%, 95 \%, 85 \%, 75 \%$, and $50 \%$ for $1 \mathrm{~min}$, respectively), then were washed in distilled water for $1 \mathrm{~min}$. Tissue sections were washed with $0.1 \mathrm{M}$ PBS on a shaker 3 times for $5 \mathrm{~min}$. After drying, the sections were put in a dark box and were incubated with working solution containing WGA-FITC $(100 \mu \mathrm{g} / \mathrm{mL}$; Sigma-Aldrich, St. Louis, MO, USA) and $\mathrm{CaCl}_{2}(1 \mathrm{mM})$ for $60 \mathrm{~min}$. After washing carefully for 3 times with PBS, tissue sections were photographed with a fluorescence microscope. Cardiomyocyte areas were quantified by morphometric analysis.

2.7. Quantitative Real-Time PCR. The total RNA of myocardium was extracted by Trizol separation reagent according to the reagent instructions. RNA sample was subjected to reverse transcription with the following procedure: $37^{\circ} \mathrm{C}$ $15 \mathrm{~min}, 85^{\circ} \mathrm{C} 5 \mathrm{~s}$, and $4^{\circ} \mathrm{C}$ forever. The cDNAs were amplified with SYBR Green Fast qPCR mix (Takara, Otsu, Shiga, Japan) using ABI StepOne PCR System (ABI, Carlsbad, CA, USA). $18 \mathrm{~S}$ was serviced as the house-keep gene. The average cycle threshold (CT) values from triplicate experiments were normalized to $18 \mathrm{~S}$, and the group of WT + NS was served as control samples. Relative mRNA expressions were calculated as the fold of control samples. The structures of all primers used are listed in Table 1.

2.8. Measurement of Superoxide Formation in Myocardium. Superoxide production in myocardium was measured with the fluorescent probe dihydroethidium (DHE). After incubation with DHE (Beyotime, Shanghai, China; $2 \mu \mathrm{M}$ ) in Krebs' 4(2-hydroxyethyl)-1-piperazineethanesulfonic acid (HEPES) buffer $\left(\mathrm{NaCl} 99 \mathrm{mM}, \mathrm{KCl} 4.7 \mathrm{mM}, \mathrm{MgSO}_{4} 1.2 \mathrm{mM}, \mathrm{KH}_{2} \mathrm{PO}_{4}\right.$ $1.0 \mathrm{mM}, \mathrm{CaCl}_{2} 1.9 \mathrm{mM}, \mathrm{NaHCO}_{3} 25 \mathrm{mM}$, glucose $11.1 \mathrm{mM}$, Na HEPES $20 \mathrm{mM}$; pH 7.4) at $37^{\circ} \mathrm{C}$ for $30 \mathrm{~min}$, myocardial sections $(5 \mu \mathrm{m})$ were examined with fluorescence microscope (Nikon, Tokyo, Japan) with excitation and emission wavelengths at $480 \mathrm{~nm}$ and $610 \mathrm{~nm}$, respectively.

Myocardial malondialdehyde (MDA) level in myocardium was measured with thiobarbituric acid method (Beyotime, Shanghai, China) and was represented as $\mathrm{nmol} / \mathrm{mg}$ protein. Myocardial total antioxidant capacity (T-AOC) was assessed with 2,2' azino-bis(3-ethylbenzthi-azoline-6sulfonic acid, ABTS) method (Beyotime, Shanghai, China) and was represented as $\mu \mathrm{mol} / \mathrm{mg}$ protein. The myocardial activity of total superoxide dismutase (SOD), $\mathrm{Cu}-\mathrm{Zn} / \mathrm{SOD}$, and $\mathrm{Mn}$-SOD was evaluated with 2-(4-Iodophenyl)-3-(4nitrophenyl)-5-(2,4-disulfophenyl)-2H-tetrazolium (WST-1) method (Beyotime, Shanghai, China) and was represented as $\mathrm{U} / \mathrm{mg}$ protein. The detailed experimental procedure was performed according to the information of the kits.

2.9. Western Blot Analysis. Mitochondria in the myocardium were collected with a Tissue Mitochondria Isolation Kit (Beyotime, Shanghai, China). Total proteins or mitochondrial proteins extracted from myocardium lysates were separated by SDS-polyacrylamide gel electrophoresis and transferred to a PVDF membrane (Millipore, Billerica, MA, USA). After blocking in TBST with $5 \%$ nonfat milk for $2 \mathrm{~h}$, protein blots were incubated overnight with antiOPA1 (1:1000; Santa Cruz Biotechnology, Santa Cruz, CA, USA), anti-DRP1, anti-extracellular-regulated protein kinase (ERK), phosphor-ERK, P38, phosphor-P38, c-Jun Nterminal kinase (JNK), phosphor-JNK $(1: 1000$, Cell Signaling Technology, Danvers, MA, USA), anti-voltage-dependent anion-selective channel proteins 1 (VDAC1, 1:1000; Santa Cruz Biotechnology, Santa Cruz, CA, USA), and antiGAPDH (1:5000, Sigma-Aldrich, St. Louis, MO, USA) at $4^{\circ} \mathrm{C}$ followed by horseradish peroxidase- (HRP-) conjugated secondary antibody at room temperature for $2 \mathrm{~h}$. Enhanced chemiluminescence (ECL, Thermo Fisher Scientific Inc., Rockford, IL, USA) was added to visualize the protein bands.

2.10. Immunofluorescence. Frozen sections of myocardium were incubated with anti-OPA1 (1:50; Santa Cruz Biotechnology, Santa Cruz, CA, USA) and anti-DRP1 (1:50; Cell Signaling Technology, Danvers, MA, USA) antibodies overnight at $4^{\circ} \mathrm{C}$ followed by Alexa Fluor 488- or Cy3conjugated IgG (1:500; Beyotime, Shanghai, China) at $37^{\circ} \mathrm{C}$ for $1 \mathrm{~h}$. The nuclei were counterstained with DAPI for several seconds. Tissue sections were photographed with a fluorescence microscope.

2.11. Statistical Analysis. All data were expressed as mean \pm standard error of the mean (SEM) and were analyzed by 1 way ANOVA followed by Bonferroni post hoc test as appropriate (Stata13.0 software, Stata Corp, College Station, TX, USA). Values of $P<0.05$ were considered as statistically significant.

\section{Result}

3.1. NaHS Inhibited Myocardial Hypertrophy and Increased SIRT3 Expression in the Mice after ISO Administration. ISO administration increased ANP and BNP mRNA expressions, and these hypertrophic indicators were significantly inhibited by NaHS (Figures 1(a)-1(b)).

We then assessed the involvement of SIRT1-SIRT7 in the protective effect of NaHS on ISO-induced myocardial hypertrophy. The mRNA expression of SIRT1 and SIRT3 was reduced in the myocardium after ISO administration, while that of SIRT2 and SIRT4-SIRT7 kept unchanged. The expression of SIRT3 mRNA, but not SIRT1, was restored by NaHS, suggesting that SIRT3, but not SIRT1, was involved in the preventive effect of NaHS on ISO-induced hypertrophy (Figure 1(c)). Further experiments confirmed that NaHS increased SIRT3 protein expression in ISO-administrated mice (Figure 1(d)).

3.2. NaHS Did Not Change Blood Pressure in Both WT Mice and SIRT3 KO Mice after ISO Administration. As well as we know, blood pressure is one of the important factors to affect cardiac hypertrophy [44]. In the present study, invasive blood pressure including SBP, DBP, and MAP showed no significant difference in different groups (Figures 2(a)-2(c)). 
TABle 1: Sequences of primers for mice.

\begin{tabular}{lcc}
\hline Gene & Sense primer & Antisense primer \\
\hline SIRT1 & $5^{\prime}$-CGGCTACCGAGGTCCATATAC-3' & $5^{\prime}$-CAGCTCAGGTGGAGGAATTGT-3' \\
SIRT2 & $5^{\prime}$-GAGCCGGACCGATTCAGAC-3' & $5^{\prime}$-AGACGCTCCTTTTGGGAACC-3' \\
SIRT3 & $5^{\prime}$-GGATTCGGATGGCGCTTGA-3' & $5^{\prime}$-CACCTGTAACACTCCCGGAC-3' \\
SIRT4 & $5^{\prime}$-GAGCATTCTTACTAGGGATTCCA-3' & $5^{\prime}$-AACGGCTAAACAGTCGGGTT-3' \\
SIRT5 & $5^{\prime}$-GCCACCGACAGATTCAGGTT-3' & $5^{\prime}$-CCACAGGGCGGTTAAGAAGT-3' \\
SIRT6 & $5^{\prime}$-CCAAATCGTCAGGTCAGGGA-3' & $5^{\prime}$-CAGAGTGGGGTACAGGGATG-3' \\
SIRT7 & $5^{\prime}$-CTAAGCGAAGCGGAGCCTAC-3' & $5^{\prime}$-GTGGAGCCCATCACAGTTCT-3' \\
ANP & $5^{\prime}$-GAGAAGATGCCGGTAGAAGA-3' & $5^{\prime}$-AAGCACTGCCGTCTCTCAGA-3' \\
BNP & $5^{\prime}$-CTGCTGGAGCTGATAAGAGA-3' & $5^{\prime}$-TGCCCAAAGCAGCTTGAGAT-3' \\
CSE & $5^{\prime}$-GCTTGGAAAAAGCAGTGGCT-3' & $5^{\prime}$-TCGTAATGGTGGCAGCAAGA-3' \\
CBS & $5^{\prime}$-AGCTGGAACCTGCTCCTTTT-3' & $5^{\prime}$-GTTGGCTCTTGAGTCCCCTC-3' \\
MPST & $5^{\prime}$-TGGTATCTGCTACCCAACGC-3' & $5^{\prime}$-CAGAGCTCGGAAAAGTTGCG-3' \\
18S & $5^{\prime}$-AGTCCCTGCCCTTTGTACACA-3' & $5^{\prime}$-CGATCCGAGGGCCTCACTA-3' \\
\hline
\end{tabular}

3.3. NaHS Enhanced Plasma $\mathrm{H}_{2} \mathrm{~S}$ Level and Myocardial $\mathrm{H}_{2} \mathrm{~S}$ Production in Both WT Mice and SIRT3 KO Mice after ISO Administration. $\mathrm{H}_{2} \mathrm{~S}$ concentration in plasma and $\mathrm{H}_{2} \mathrm{~S}$ production in myocardium was decreased in ISO-administrated mice, which was restored by NaHS in both WT mice and SIRT3 KO mice (Figures 3(a)-3(b)). ISO also reduced CSE mRNA expression, which was rescued by NaHS in all the mice (Figure 3(c)). There was no significant difference in the expression of CBS and MPST mRNA in different groups (Figures 3(d)-3(e)).

3.4. NaHS Improved Cardiac Configuration in WT Mice but Not in SIRT3 KO Mice after ISO Administration. In order to assess the effect of $\mathrm{H}_{2} \mathrm{~S}$ on cardiac hypertrophy in mice, echocardiography was used to detect the cardiac configuration. It was found that after two weeks of ISO administration, the thickness of IVS and LVPW significantly increased, which was reduced by NaHS in WT mice. However, NaHS failed to decrease IVS and LVPW thickness in SIRT3 KO mice (Figures 4(a)-4(c)). There was no statistical difference between EF and FS in each group (Figures 4(d)-4(e)).

3.5. NaHS Decreased Cardiac Indexes in WT Mice but Not in SIRT3 KO Mice after ISO Administration. After echocardiography, the cardiac index was measured. ISO administration increased HW, HMI, LVMI, and LVW/TL, which was attenuated by NaHS in WT mice. However, the inhibitory effect on cardiac index by NaHS was unavailable in SIRT3 KO mice (Figures 5(a)-5(d)).

3.6. NaHS Attenuated Myocardial Hypertrophy in WT Mice but Not in SIRT3 KO Mice after ISO Administration. WGA staining was used to measure the cross-sectional areas of cardiomyocytes. It was found that cell areas were increased after 2-week ISO administration. NaHS reduced the areas of cardiomyocytes in WT mice but not in SIRT3 KO mice
(Figures 6(a)-6(b)). NaHS also alleviated two hypertrophic genes ANP and BNP expressions in WT mice but not in SIRT3 KO mice (Figure 6(c)).

3.7. NaHS Suppressed Oxidative Stress in WT Mice but Not in SIRT3 KO Mice after ISO Administration. After ISO administration, myocardial DHE fluorescence and level of MDA were elevated, suggesting more superoxide production and severe oxidative stress. After NaHS pretreatment, above two parameters for oxidative stress were reduced significantly in WT mice but not in SIRT3 KO mice (Figures 7(a)-7(b)). ISO also impaired myocardial T-AOC and total SOD activity (especially $\mathrm{Mn}-\mathrm{SOD}$ but not $\mathrm{Cu}-\mathrm{Zn} / \mathrm{SOD}$ ), which was restored by NaHS in WT mice but not in SIRT3 KO mice (Figures $7(\mathrm{c})-7(\mathrm{~d})$ ).

3.8. NaHS Alleviated Myocardial ERK Phosphorylation in WT Mice but Not in SIRT3 KO Mice after ISO Administration. Mitogen-activated protein kinases (MAPKs) family (including ERK1/2, P38, and JNK) is one of the most important downstream signal pathways of oxidative stress [45]. The present study found that phosphorylation of ERK, but not P38 or JNK, was enhanced in the myocardium of mice after ISO administration, while NaHS diminished myocardial ERK phosphorylation in WT mice but not in SIRT3 KO mice after ISO administration (Figures 8(a)-8(c)).

3.9. NaHS Enhanced OPA1 Expression but Attenuated DRP1 Formation in WT Mice but Not in SIRT3 KO Mice after ISO Administration. OPA1 is a vital protein to maintain mitochondrial fusion, while DRP1 is important to regulate mitochondrial fission [46]. Immunofluorescence and western blot were used to detect the expression of the above two proteins. We found that OPAl fluorescent intensity and protein expression were impaired, but DRP1 formation was increased in hypertrophic myocardium after ISO 


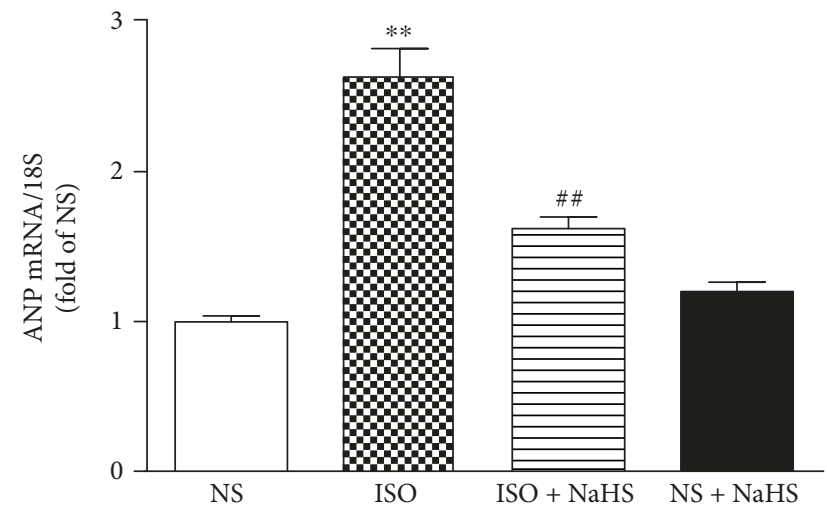

(a)

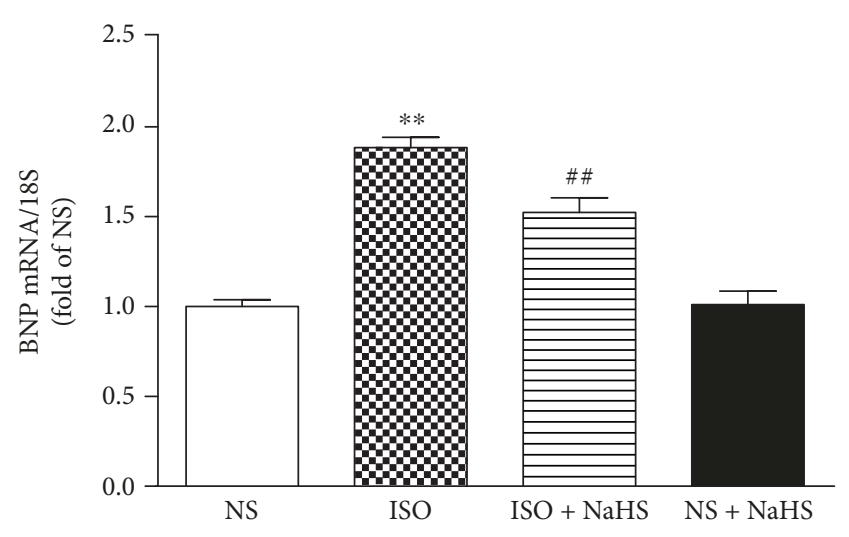

(b)
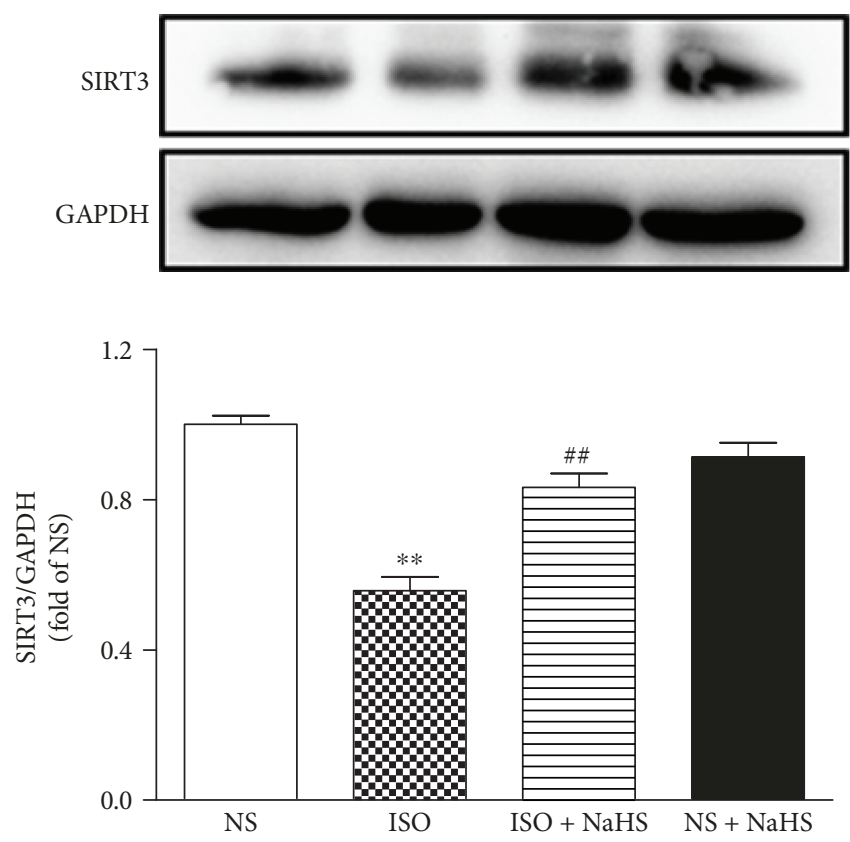

(d)

FIGURE 1: Effect of NaHS on myocardial hypertrophy and SIRT3 expression in the mice after ISO administration. Male C57BL/6 mice at 10 weeks of age were administrated with NaHS $(50 \mu \mathrm{mol} / \mathrm{kg} / \mathrm{d})$ or normal saline (NS) once daily. After 2 weeks, the mice were given isoproterenol (ISO, $60 \mathrm{mg} / \mathrm{kg}$ ) by intraperitoneal injection followed by NaHS or NS administration once daily for another 2 weeks. (a-b) ANP and BNP mRNA expressions were quantified by real-time PCR. 18S was serviced as a house-keep gene. (c) Quantification of SIR2 family (SIRT1-SIRT7) mRNA expression was assessed by real-time PCR. 18S was serviced as a house-keep gene. (d) The expression of SIRT3 protein in the myocardium of mice was measured by western blot. GAPDH was serviced as a loading control. Plots represent the mean \pm SEM; $n=6$. Statistical significance: ${ }^{* *} P<0.01$ compared with NS; ${ }^{\#} P<0.01$ compared with ISO.

administration. Moreover, NaHS enhanced OPA1 expression but attenuated DRP1 formation in WT mice but not in SIRT3 KO mice after ISO administration (Figures 9(a)-9(d)).

\section{Discussion}

Hypertension, as the key risk factor of cardiovascular disease, is the main cause of death in patients suffering from cardiovascular disease worldwide [47]. Studies have indicated that $\mathrm{H}_{2} \mathrm{~S}$ played an important role in hypertension. General knockout of CSE, as the main enzyme for $\mathrm{H}_{2} \mathrm{~S}$ production in cardiovascular system, resulted in lower $\mathrm{H}_{2} \mathrm{~S}$ content in serum, heart, aorta, and other tissues and impaired vascular diastolic function and higher blood pressure. Exogenous NaHS dosage dependently reduced blood pressure in CSE knockout mice [48]. $\mathrm{H}_{2} \mathrm{~S}$ supplementation attenuated hypertension in different hypertensive animal models [17]. Previous studies have found that $\mathrm{H}_{2} \mathrm{~S}$ donor GYY4137 prevented NG-nitro-L-arginine methyl ester- (L-NAME-) induced hypertension. The administration of GYY4137 significantly decreased blood pressure in SHR, and there was a gradual recovery without sudden rebound if GYY4137 was stopped 


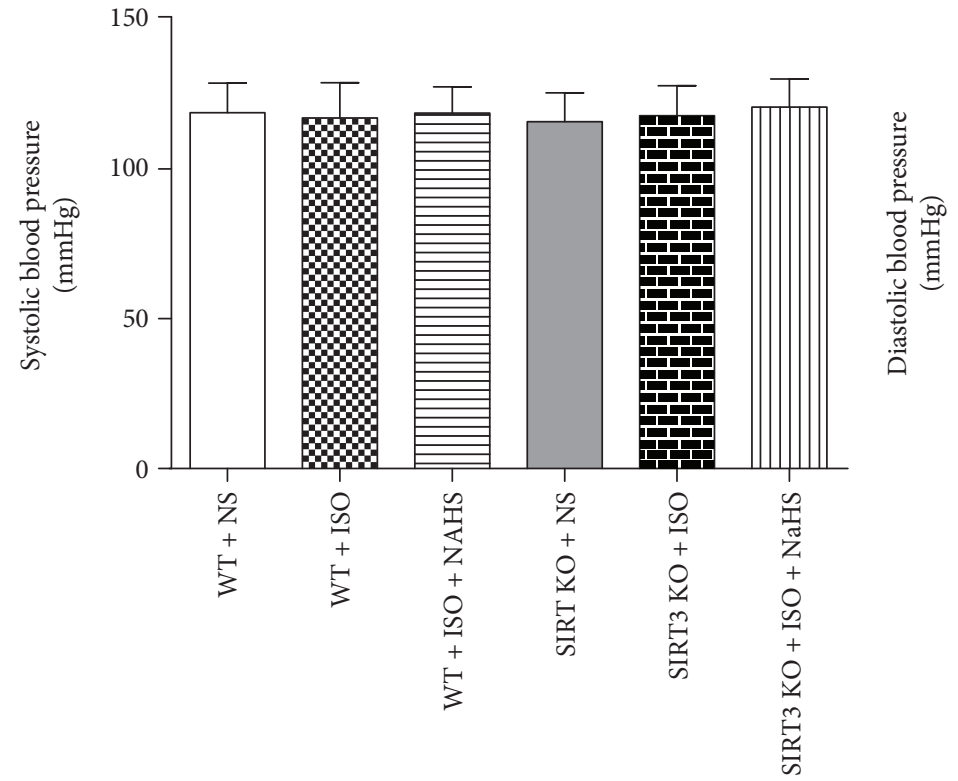

(a)

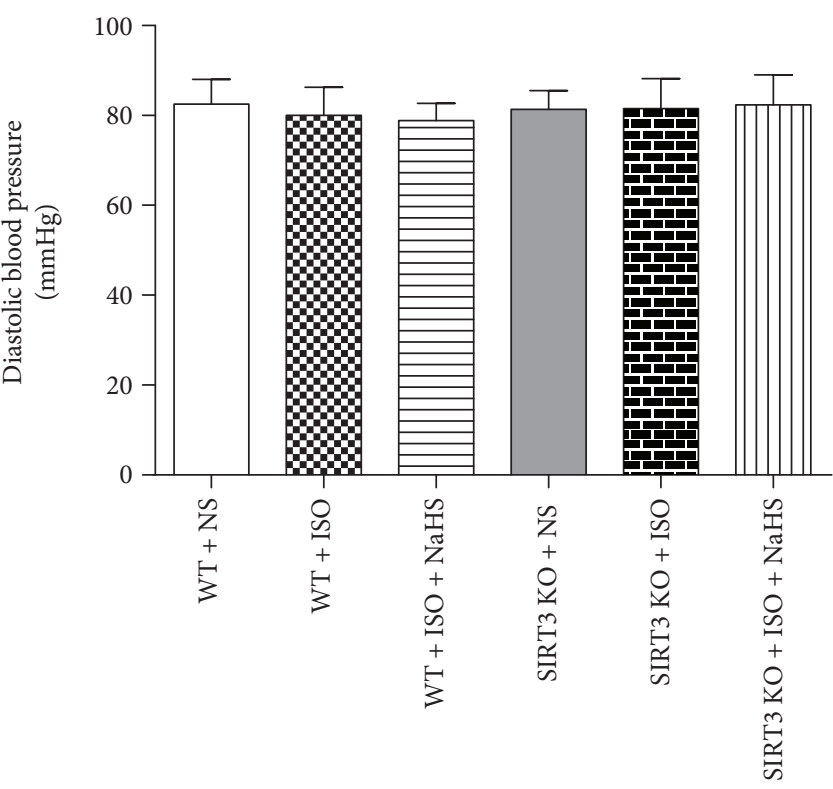

(b)

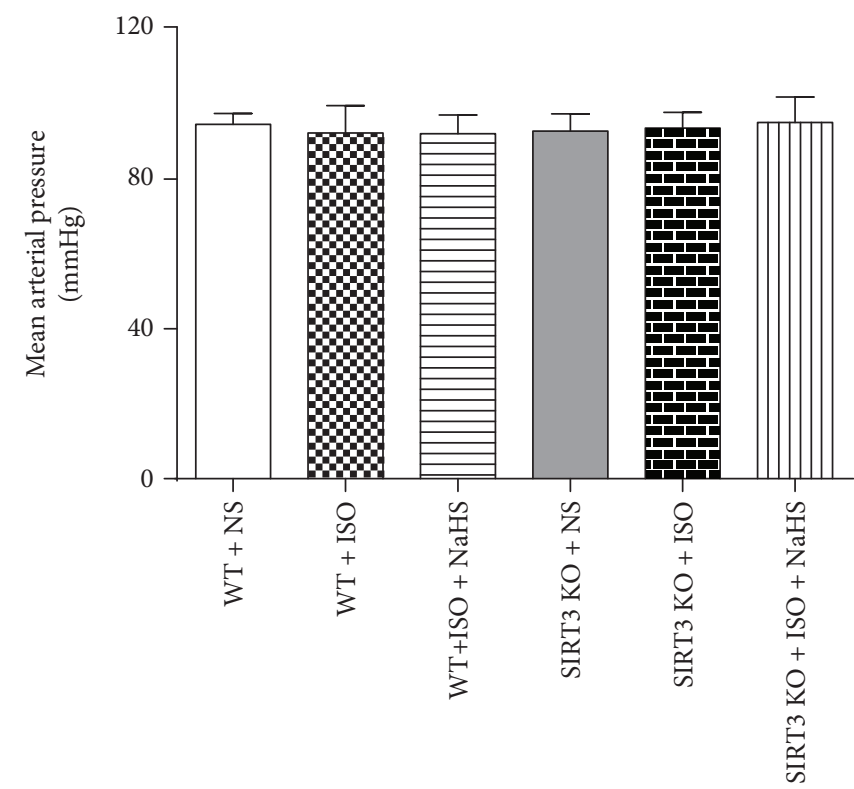

(c)

Figure 2: Effect of NaHS on blood pressure in WT mice and SIRT3 KO mice after ISO administration. Male 129S1/SvImJ (WT) and SIRT3 knockout $(\mathrm{KO})$ mice at 10 weeks of age were administrated with NaHS $(50 \mu \mathrm{mol} / \mathrm{kg} / \mathrm{d})$ or normal saline (NS) once daily. After 2 weeks, the mice were given isoproterenol (ISO, $60 \mathrm{mg} / \mathrm{kg}$ ) by intraperitoneal injection followed by NaHS or NS administration once daily for another 2 weeks. $(\mathrm{a}-\mathrm{c})$ Invasive arterial blood pressures, including systolic blood pressure (SBP), diastolic blood pressures (DBP), and mean arterial pressure (MAP), were measured from left carotid artery. Plots represent the mean \pm SEM; $n=6$.

[49]. GYY4137 also reduced blood pressure in angiotensin IIinduced hypertensive mice [50] and in SHR [20]. In normotensive animals, $\mathrm{Na}_{2} \mathrm{~S} \cdot 9 \mathrm{H}_{2} \mathrm{O}$ saline solution at doses of $100 \mathrm{mg} / \mathrm{kg}$ and $300 \mathrm{mg} / \mathrm{kg}$, but not of $30 \mathrm{mg} / \mathrm{kg}$, induced a significant reduction on blood pressure in Wistar Kyoto rats. The administration of $\mathrm{Na}_{2} \mathrm{~S}$ in doses of $0.1-0.5 \mathrm{mg} / \mathrm{kg}$ with intravenous injection significantly decreased MAP in the anesthetized Sprague-Dawley rat [51]. In our present study, the reduction on SIRT1 after ISO administration could not be restored by NaHS, suggesting that SIRT1 is not involved in the protective effect by $\mathrm{H}_{2} \mathrm{~S}$ on ISO-induced myocardial hypertrophy. NaHS pretreatment only enhanced SIRT3 mRNA levels in the presence of ISO stimulation. Therefore, we focused on SIRT3 in subsequent experiments. Moreover, NaHS $(50 \mu \mathrm{mol} / \mathrm{kg} / \mathrm{d})$ supplement restored endogenous $\mathrm{H}_{2} \mathrm{~S}$ level, but NaHS did not influence blood pressure in both WT mice and SIRT3 KO mice with normotension. It suggested that the different effects of NaHS on ISO-induced myocardial hypertrophy between WT mice and SIRT3 KO mice were not due to blood pressure or endogenous $\mathrm{H}_{2} \mathrm{~S}$ level. 


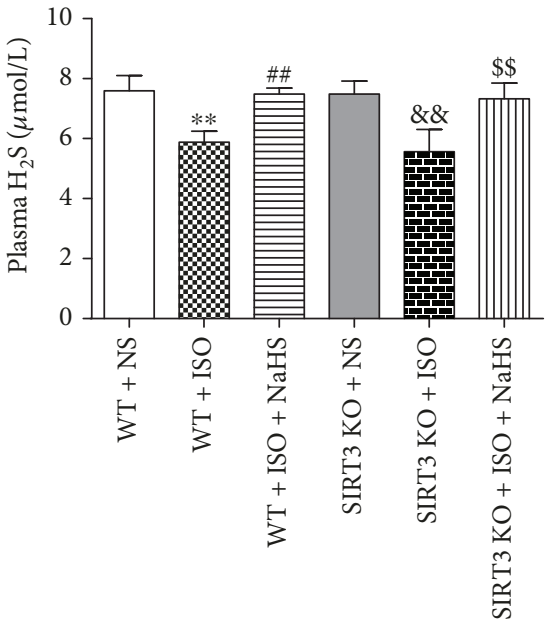

(a)

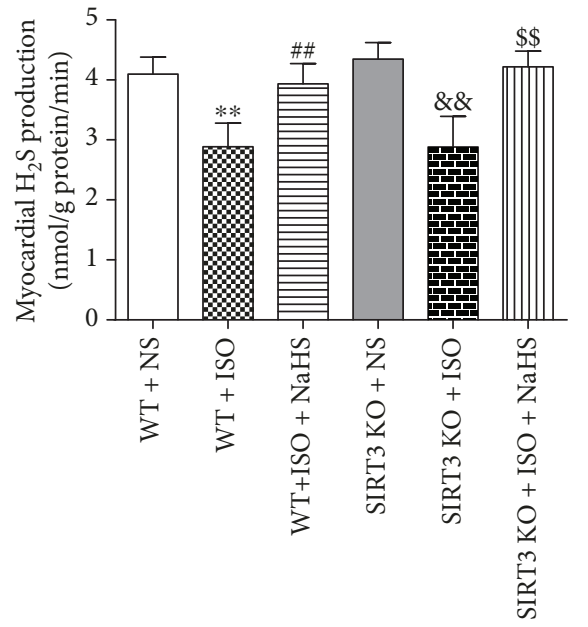

(b)

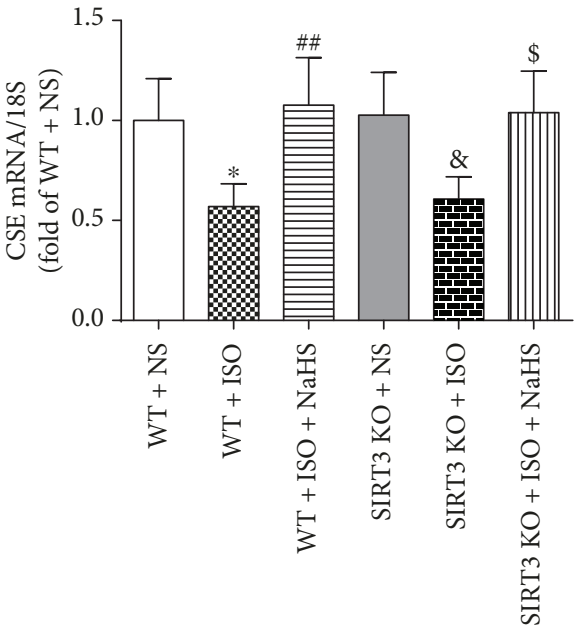

(c)

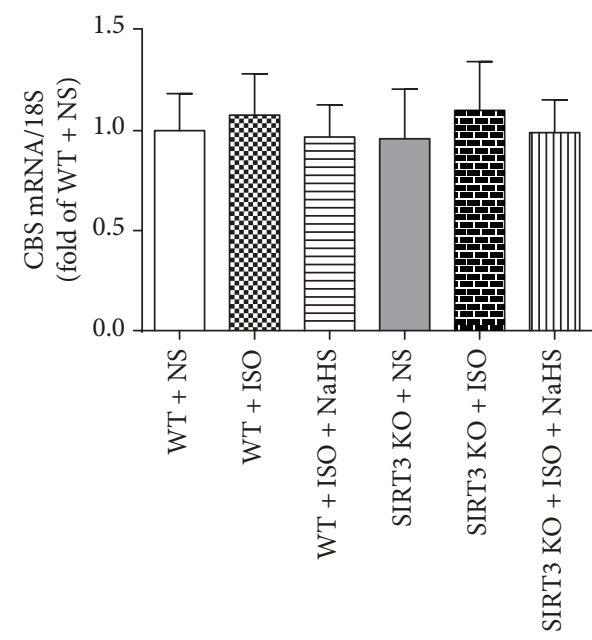

(d)

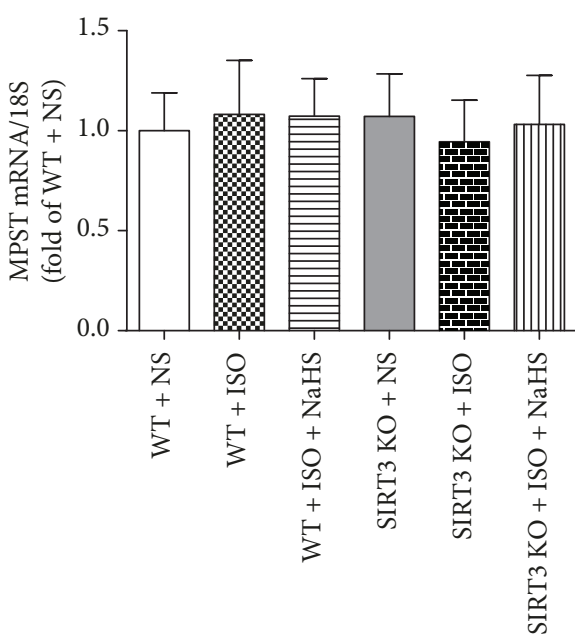

(e)

FIgURE 3: Effect of NaHS on plasma $\mathrm{H}_{2} \mathrm{~S}$ level and myocardial $\mathrm{H}_{2} \mathrm{~S}$ production in WT mice and SIRT3 KO mice after ISO administration. Male 129S1/SvImJ (WT) and SIRT3 knockout (KO) mice at 10 weeks of age were administrated with NaHS $(50 \mu \mathrm{mol} / \mathrm{kg} / \mathrm{d})$ or normal saline (NS) once daily. After 2 weeks, the mice were given isoproterenol (ISO, $60 \mathrm{mg} / \mathrm{kg}$ ) by intraperitoneal injection followed by NaHS or NS administration once daily for another 2 weeks. (a-b) Plasma $\mathrm{H}_{2} \mathrm{~S}$ level and myocardial $\mathrm{H}_{2} \mathrm{~S}$ production were measured with $\mathrm{H}_{2} \mathrm{~S}$ specific microelectrodes connected to the free radical analyzer. (c-e) CSE, CBS, and MPST mRNA expressions were measured by quantitative realtime PCR. $18 \mathrm{~S}$ was serviced as a house-keep gene. Plots represent the mean \pm SEM; $n=6$. Statistical significance: ${ }^{*} P<0.05,{ }^{* *} P<0.01$ compared with WT $+\mathrm{NS}$; ${ }^{\# \# P} P 0.01$ compared with WT $+\mathrm{ISO} ;{ }^{\&} P<0.05,{ }^{\& \&} P<0.01$ compared with SIRT3 KO + NS; ${ }^{\$} P<0.05, \$ \$ P<0.01$ compared with SIRT3 $\mathrm{KO}+$ ISO.

During hypertension, cardiomyocyte structure, function, and genetic phenotype are subjected into adaptive changes to result in myocardial hypertrophy gradually [52-54]. But there is controversy on the inhibitory effect of $\mathrm{H}_{2} \mathrm{~S}$ against cardiac hypertrophy. Some studies have confirmed that NaHS inhibited abdominal aortic constriction-induced cardiac hypertrophy [55]. NaHS alleviated myocardial hypertrophy via angiotensin type 1 receptor in 2-kidney 1-clip rats [56]. NaHS administration prior to transverse aortic constriction in mice or angiotensin II exposure in cardiomyocyte protected against hypertrophy via a PI3K/Akt-dependent Nrf2 pathway activation [57]. NaHS also inhibited high-salt diet-induced myocardial hypertrophy in rats [58]. However, it was also found that NaHS treatment for 3 months did not reduce the left ventricular weight index and other important indicators of cardiac hypertrophy [59]. The divergent effects of $\mathrm{H}_{2} \mathrm{~S}$ on cardiac hypertrophy might be due to the model types or degrees of myocardial hypertrophy, the pharmacokinetic characteristics of $\mathrm{H}_{2} \mathrm{~S}$ donor, or the times of $\mathrm{H}_{2} \mathrm{~S}$ administration. In our present study, cardiac configuration, cardiac index, cardiomyocyte areas, and hypertrophic genes expression suggested that NaHS effectively attenuated myocardial hypertrophy in WT mice but not in SIRT3 KO mice. Associated with the similar effect on blood pressure and $\mathrm{H}_{2} \mathrm{~S}$ concentration in all the mice, SIRT3 might be the critical factor on the protective effects against myocardial hypertrophy by $\mathrm{H}_{2} \mathrm{~S}$.

$\mathrm{H}_{2} \mathrm{~S}$ has a potential ability of antioxidative stress in different tissues. Previous study found NaHS inhibited the levels of MDA and 4-hydroxy-2-trans-nonenal (4-HNE) 

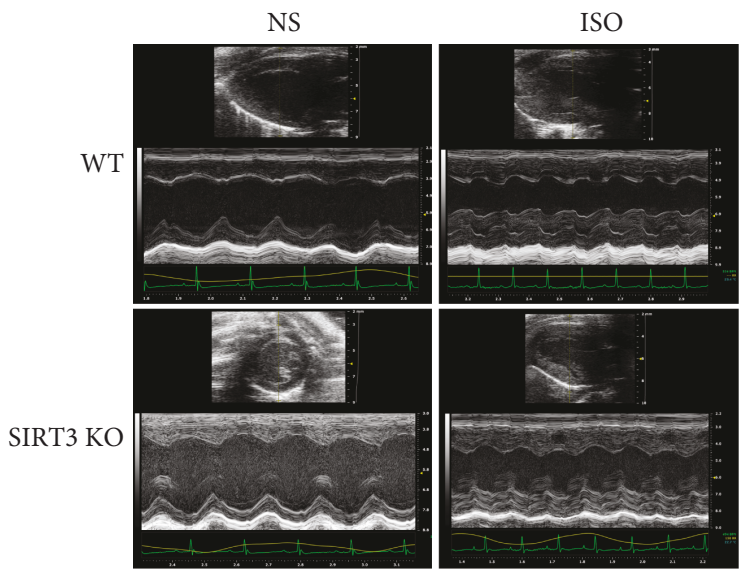

ISO + NaHS

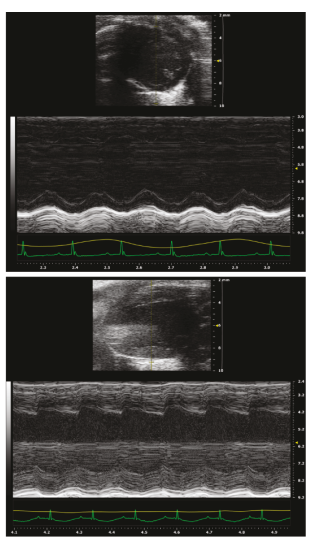

(a)

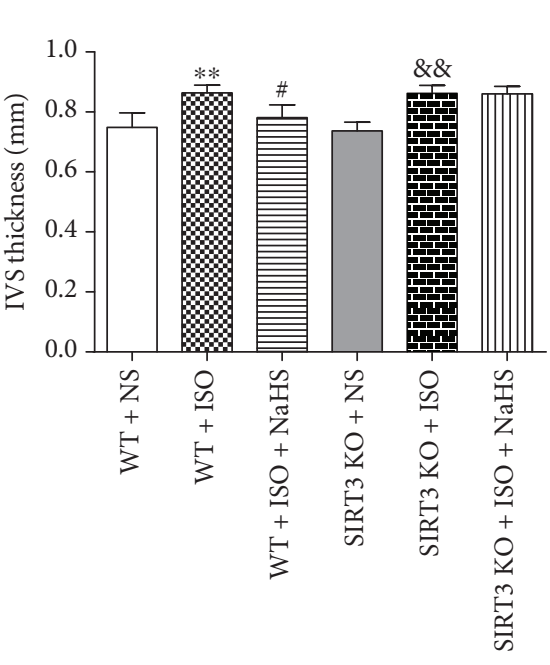

(b)

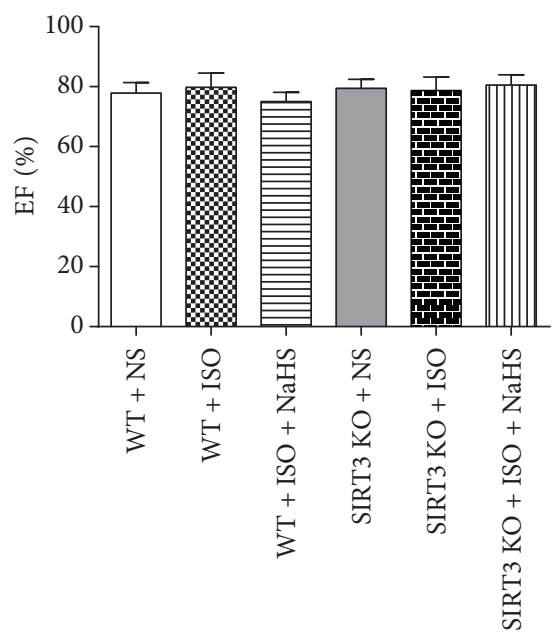

(d)

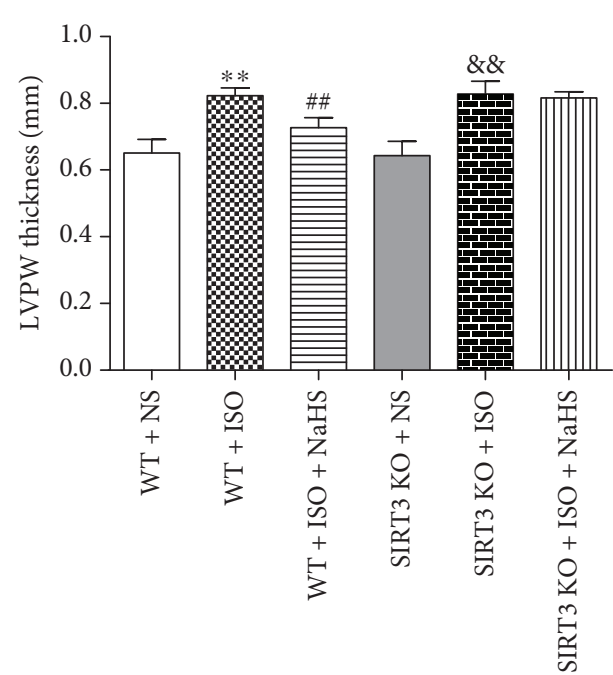

(c)

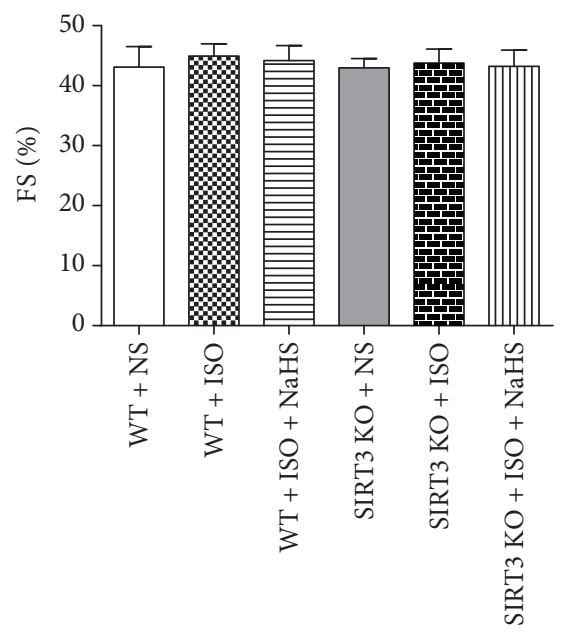

(e)

FIGURE 4: Effect of NaHS on cardiac configuration and function in WT mice and SIRT3 KO mice after ISO administration. Male 129S1/SvImJ (WT) and SIRT3 knockout (KO) mice at 10 weeks of age were administrated with NaHS ( $50 \mu \mathrm{mol} / \mathrm{kg} / \mathrm{d})$ or normal saline (NS) once daily. After 2 weeks, the mice were given isoproterenol (ISO, $60 \mathrm{mg} / \mathrm{kg}$ ) by intraperitoneal injection followed by NaHS or NS administration once daily for another 2 weeks. (a) Representative 2-D M-mode echocardiograms of the heart by echocardiography. (b-c) IVS and LVPW thickness were quantified by echocardiography. (d-e) EF and FS were quantified by echocardiography. Plots represent the mean \pm SEM; $n=6$. Statistical significance: ${ }^{* *} P<0.01$ compared with WT + NS; ${ }^{\#} P<0.05,{ }^{\# \#} P<0.01$ compared with WT + ISO; ${ }^{\& \&} P<0.01$ compared with SIRT3 KO + NS. 


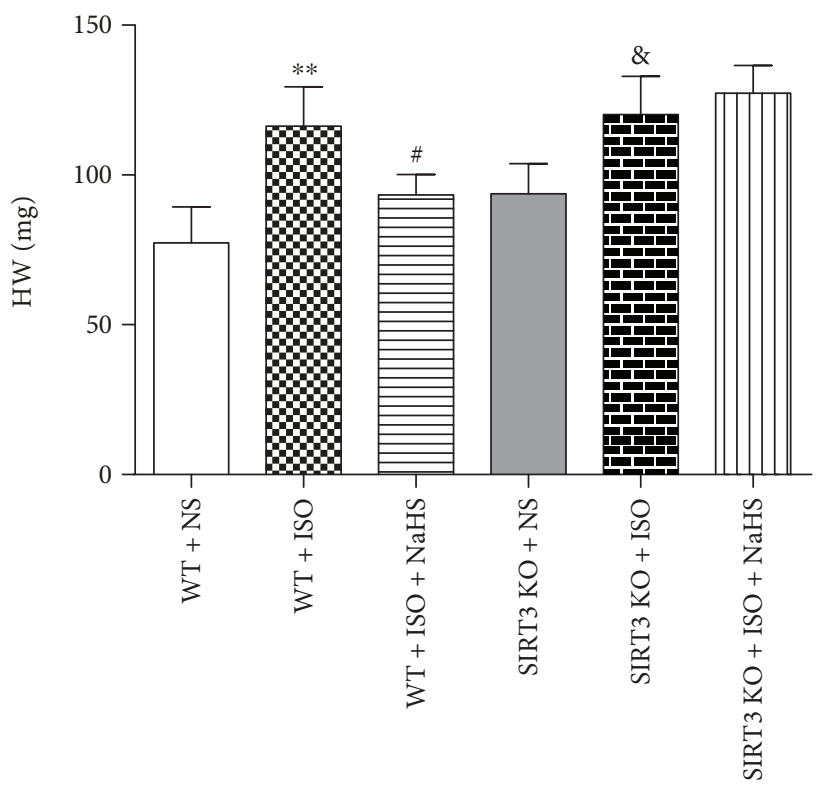

(a)

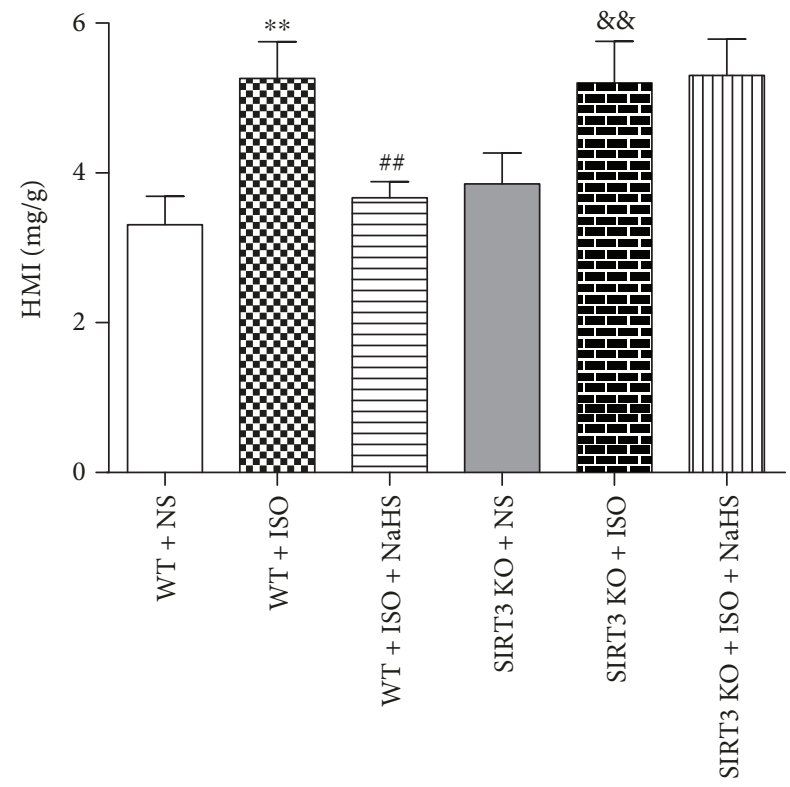

(b)

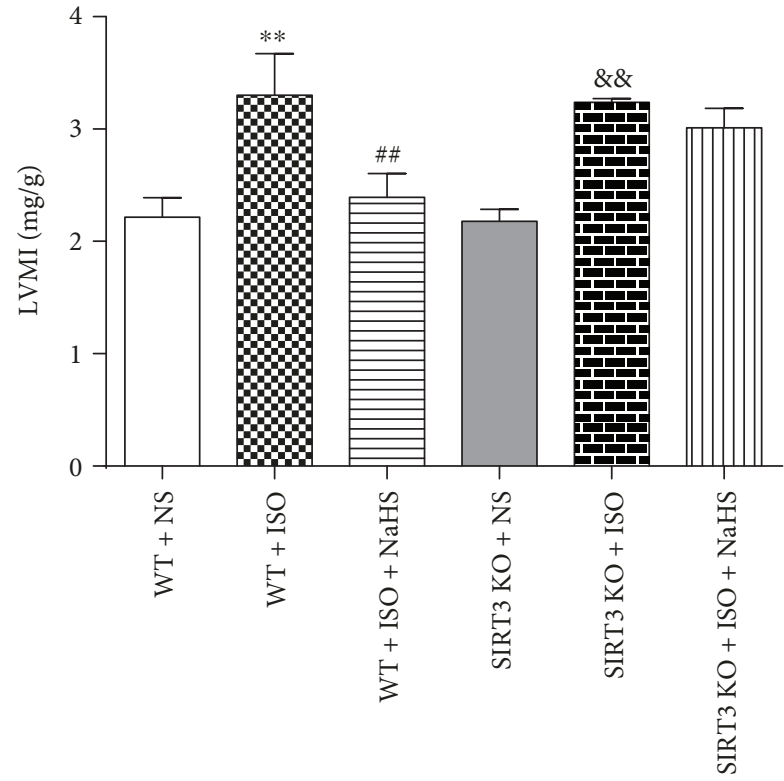

(c)

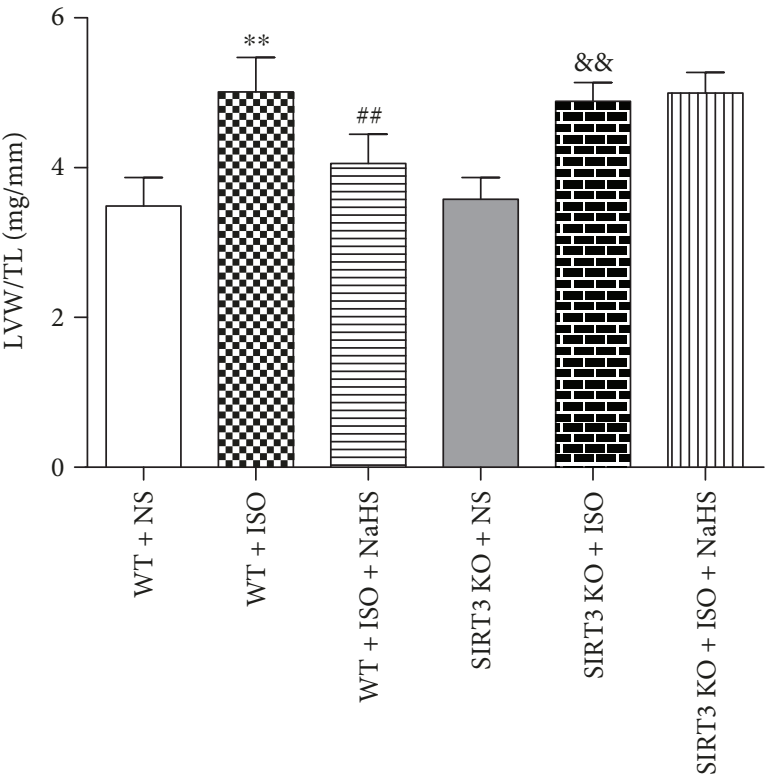

(d)

FIGURE 5: Effect of NaHS on cardiac indexes in WT mice and SIRT3 KO mice after ISO administration. Male 129S1/SvImJ (WT) and SIRT3 knockout (KO) mice at 10 weeks of age were administrated with NaHS (50 $\mu \mathrm{mol} / \mathrm{kg} / \mathrm{d})$ or normal saline (NS) once daily. After 2 weeks, the mice were given isoproterenol (ISO, $60 \mathrm{mg} / \mathrm{kg}$ ) by intraperitoneal injection followed by NaHS or NS administration once daily for another 2 weeks. (a) The heart was collected, and the heart weight (HW) was measured. (b-c) The heart mass index (HMI) and left ventricular mass index (LVMI) were normalized by body weight (BW). (d) The tibia length (TL) was measured, and the ratio of LVW to TL (LVW/TL) were calculated. Plots represent the mean \pm SEM; $n=6$. Statistical significance: ${ }^{* *} P<0.01$ compared with WT $+\mathrm{NS}$; $P<0.05$, \#\# $P<0.01$ compared with WT + ISO; ${ }^{\&} P<0.05,{ }^{\& \&} P<0.01$ compared with SIRT3 KO + NS.

in hippocampus of chronic unpredictable mild stressinduced rats [60]. Our latest research demonstrated that $\mathrm{H}_{2} \mathrm{~S}$ inhibited the generation of superoxide anion in artery of streptozotocin-administrated $\mathrm{LDLr}^{-/-}$mice and in high glucose and oxidized LDL-stimulated primary peritoneal macrophages, which indicated that $\mathrm{H}_{2} \mathrm{~S}$ suppressed oxidative stress in diabetes-accelerated atherosclerosis [24]. $\mathrm{H}_{2} \mathrm{~S}$ reduced the accumulation of intracellular ROS in alcoholic fatty liver [61], ameliorated oxidative injury in hypoxia/ reoxygenation-treated aging cardiomyocytes [62], inhibited renal oxidative stress to alleviate high-salt diet-induced renal injury [63], and lightened smoke inhalation-induced oxidative stress and lung injury [64]. More importantly, $\mathrm{H}_{2} \mathrm{~S}$ exerts cardioprotective effect through antioxidant effects. $\mathrm{H}_{2} \mathrm{~S}$ reduced the ROS generation and accumulation in myocardium after myocardial ischemia reperfusion 

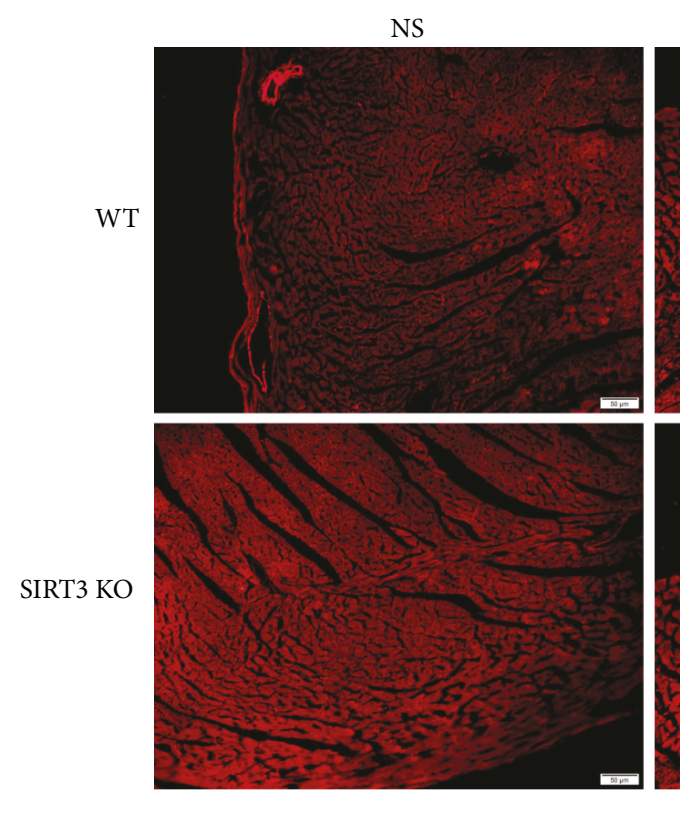

ISO
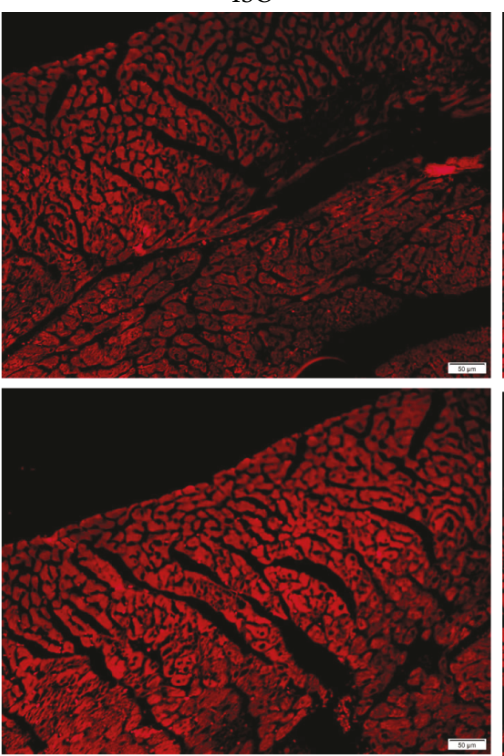

(a)

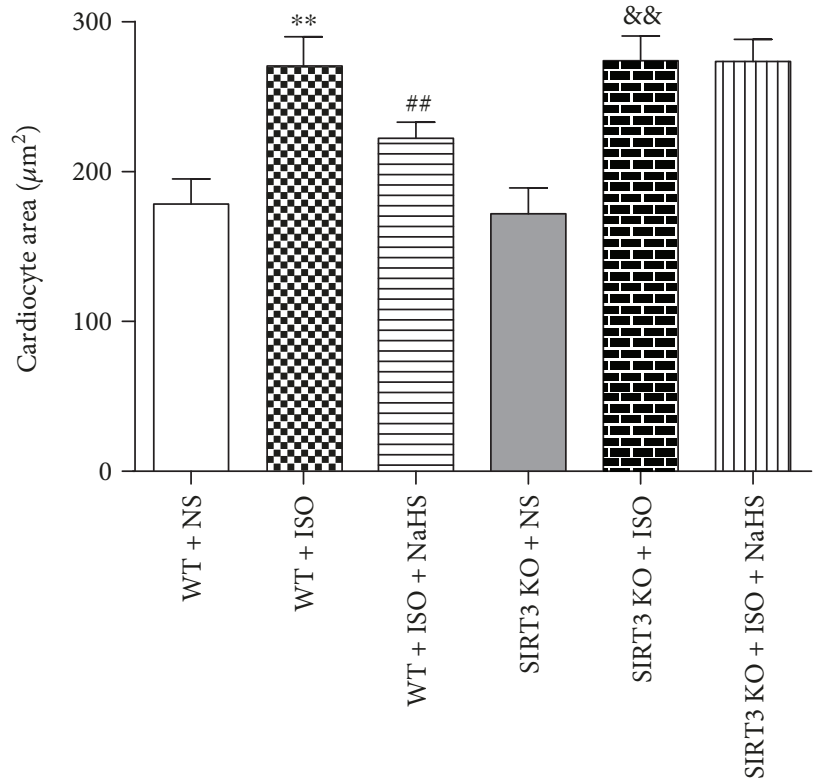

(b)

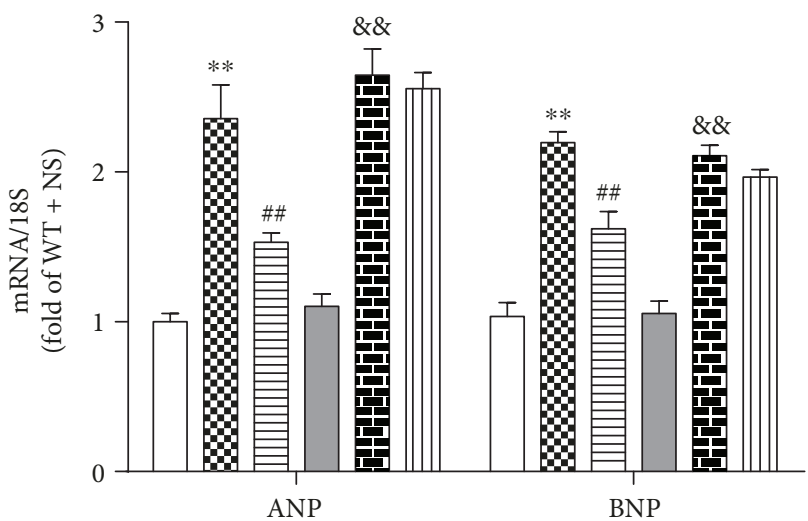

$\square \mathrm{WT}+\mathrm{NS}$

$8 \mathbf{W T}+\mathrm{ISO}$

$\mathrm{WT}+\mathrm{ISO}+\mathrm{NaHS}$

SIRT3 $\mathrm{KO}+\mathrm{NS}$

포 SIRT3 $\mathrm{KO}+\mathrm{ISO}$

III) SIRT3 $\mathrm{KO}+\mathrm{ISO}+\mathrm{NaHS}$
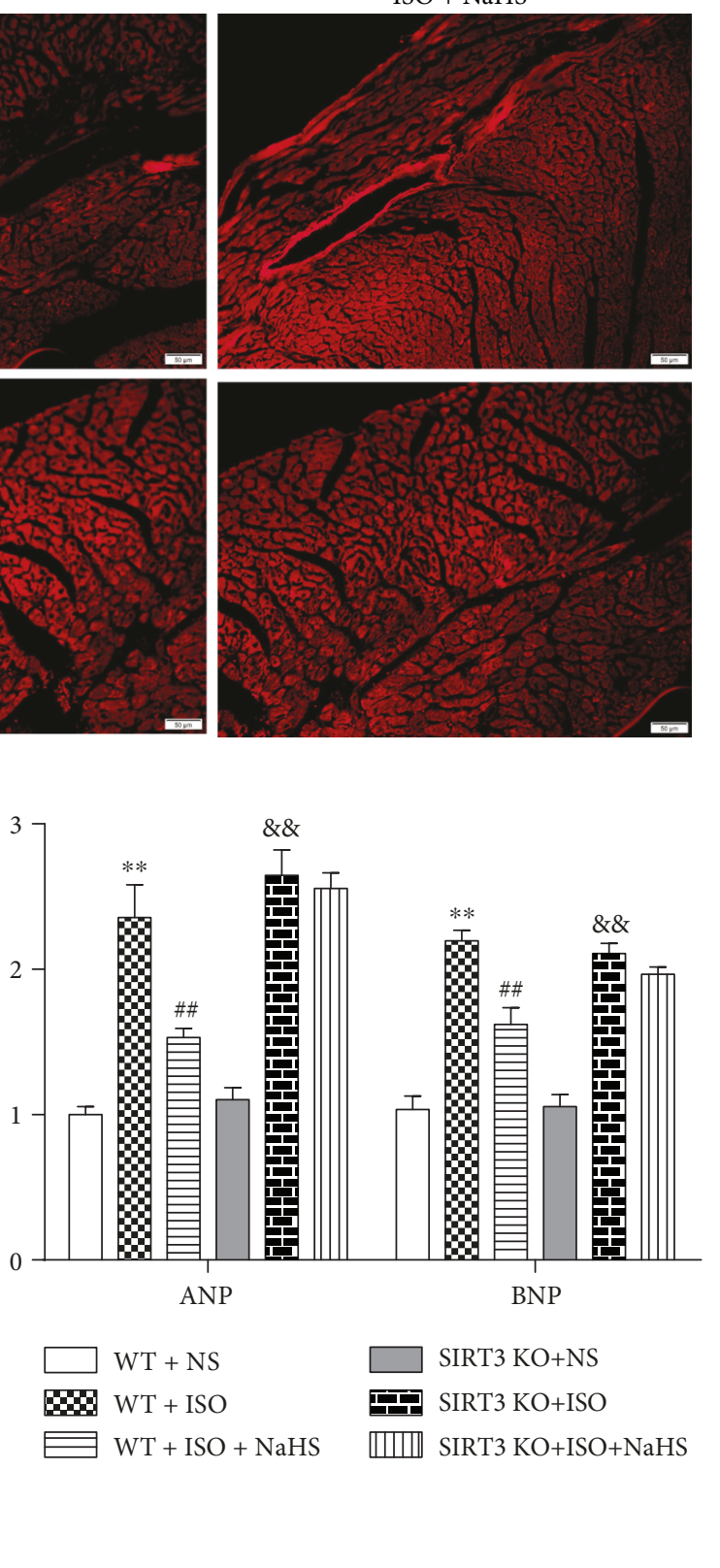

(c)

FIGURE 6: Effect of NaHS on myocardial hypertrophy in WT mice and SIRT3 KO mice after ISO administration. Male 129S1/SvImJ (WT) and SIRT3 knockout (KO) mice at 10 weeks of age were administrated with NaHS ( $50 \mu \mathrm{mol} / \mathrm{kg} / \mathrm{d}$ ) or normal saline (NS) once daily. After 2 weeks, the mice were given isoproterenol (ISO, $60 \mathrm{mg} / \mathrm{kg}$ ) by intraperitoneal injection followed by NaHS or NS administration once daily for another 2 weeks. (a) The myocardium of mice was stained with WGA and was photographed with a fluorescence microscope. Bar $=50 \mu \mathrm{m}$. (b) Cardiomyocyte area was quantified by morphometric analysis. (c) ANP and BNP mRNA expressions were quantified by real-time PCR. $18 \mathrm{~S}$ was serviced as a house-keep gene. Plots represent the mean \pm SEM; $n=6$. Statistical significance: ${ }^{* *} P<0.01$ compared with WT + NS; ${ }^{\# \#} P<0.01$ compared with WT + ISO; ${ }^{\& \&} P<0.01$ compared with SIRT3 KO + NS.

[65]. $\mathrm{Na}_{2} \mathrm{~S}$ protected against oxygen-free radical induced myocardial cell death [66]. Our present study confirmed that NaHS decreased MDA levels in serum, attenuated superoxide anion production, and restored T-AOC and SOD activity in the heart of the WT mice after ISO administration, which verified the antioxidative ability of $\mathrm{NaHS}$ in myocardium hypertrophy.
Until now, the effect of $\mathrm{H}_{2} \mathrm{~S}$ on MAPK signaling pathway, which is one of the most important downstream signal pathways of oxidative stress, has not been completely consistent under different conditions. In smooth muscle cells, exogenous $\mathrm{H}_{2} \mathrm{~S}$ or overexpression of CSE activated ERK and p38 pathway [67]. $\mathrm{H}_{2} \mathrm{~S}$ increased ERK and P38 activity to induce apoptosis in human arterial smooth muscle cells, which 

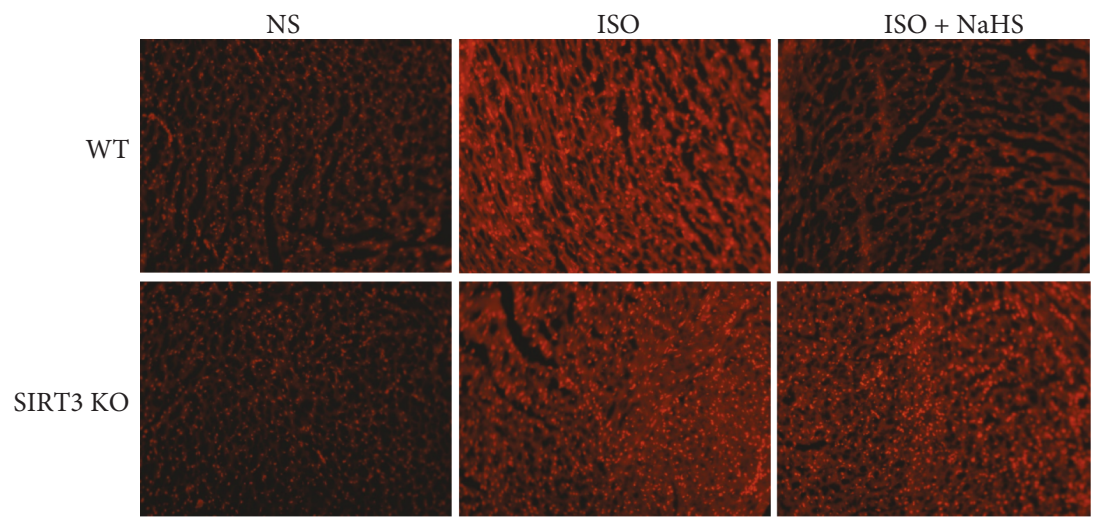

(a)

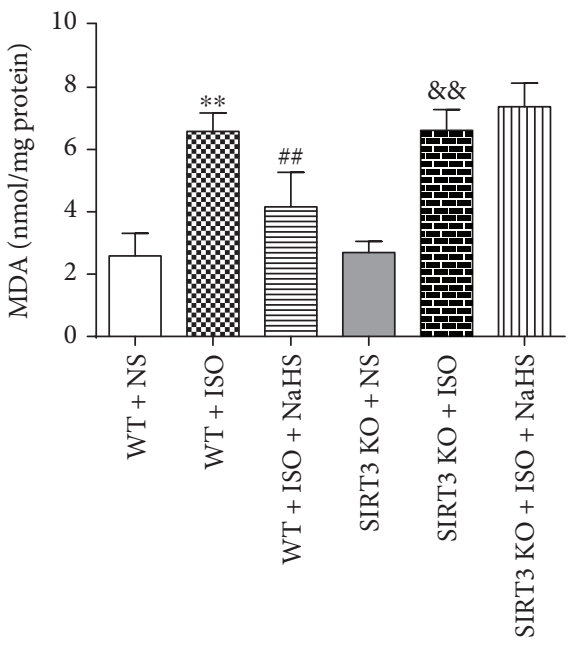

(b)

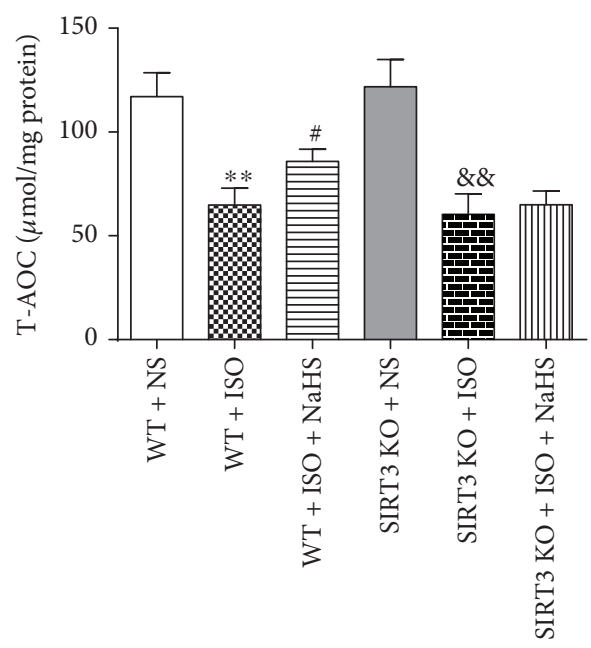

(c)

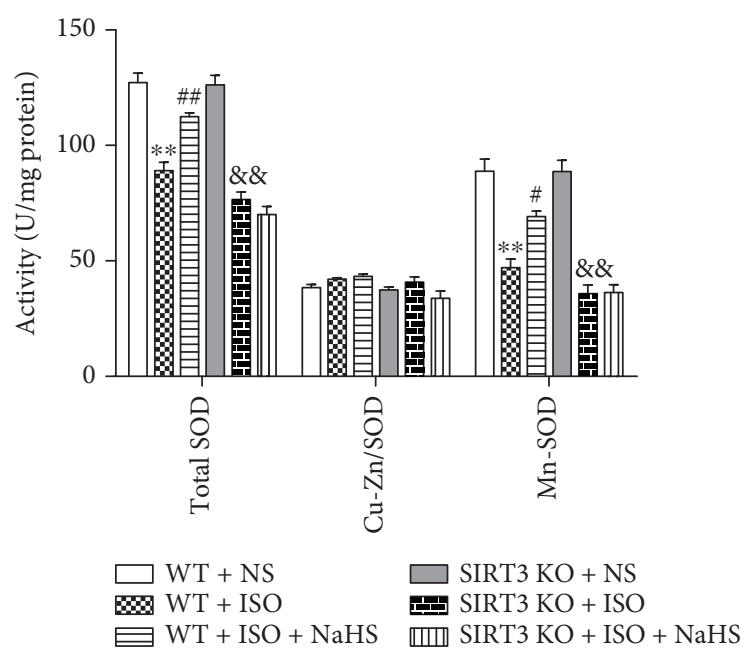

(d)

FIGURE 7: Effect of NaHS on oxidative stress in WT mice and SIRT3 KO mice after ISO administration. Male 129S1/SvImJ (WT) and SIRT3 knockout (KO) mice at 10 weeks of age were administrated with NaHS (50 $\mu \mathrm{mol} / \mathrm{kg} / \mathrm{d})$ or normal saline (NS) once daily. After 2 weeks, the mice were given isoproterenol (ISO, $60 \mathrm{mg} / \mathrm{kg}$ ) by intraperitoneal injection followed by NaHS or NS administration once daily for another 2 weeks. (a) The myocardium of mice was stained with DHE and was photographed with a fluorescence microscope. (b) MDA level in the myocardium was measured. (c) T-AOC of the myocardium was assessed. (d) SOD, Cu-Zn/SOD, and Mn-SOD activity of myocardium were evaluated. Plots represent the mean \pm SEM; $n=6$. Statistical significance: ${ }^{* *} P<0.01$ compared with $\mathrm{WT}+\mathrm{NS}$; ${ }^{\#} P<0.05$, ${ }^{\# \#} P<0.01$ compared with WT + ISO; \&\& $P<0.01$ compared with SIRT3 KO + NS. 

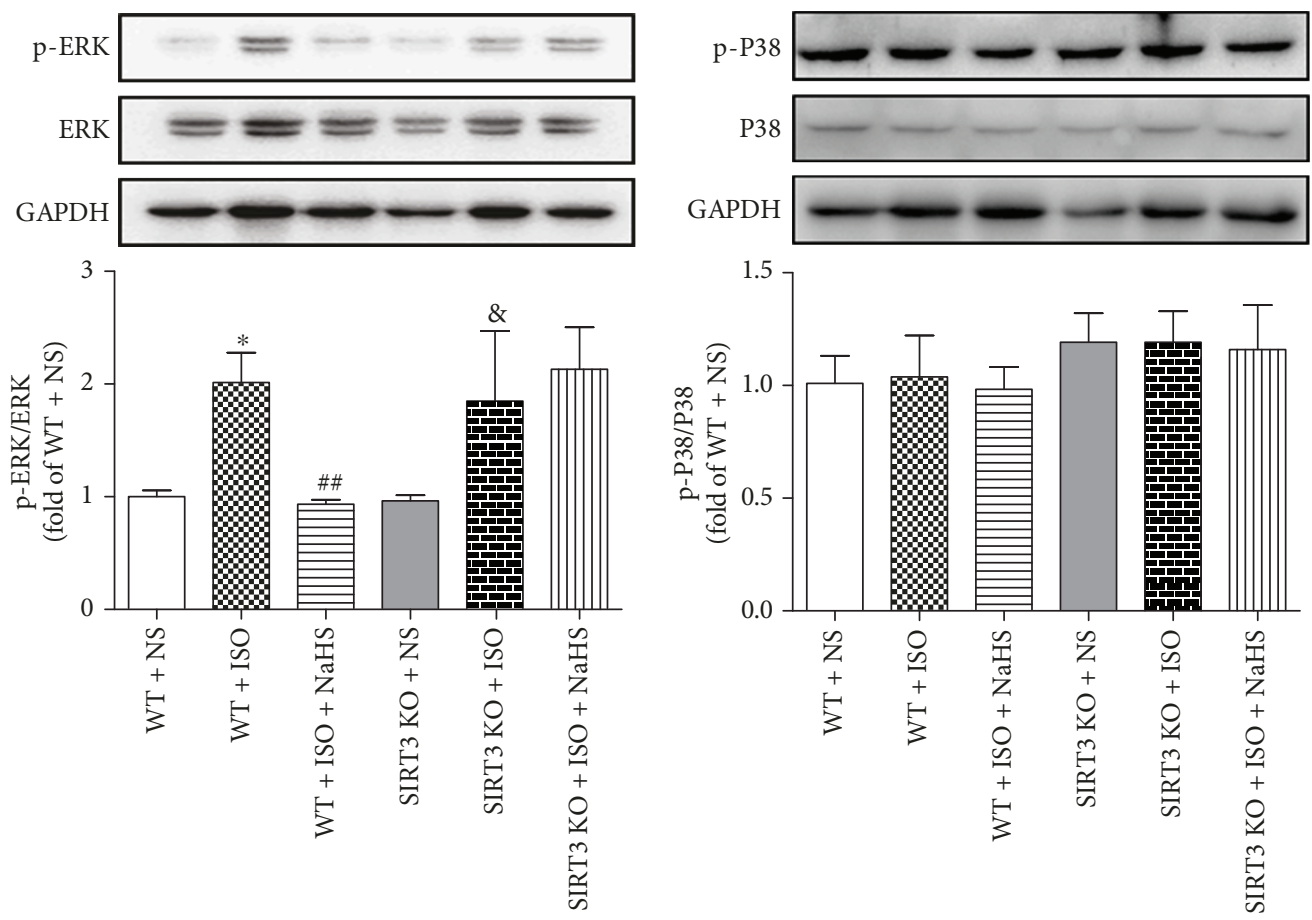

(a)

(b)

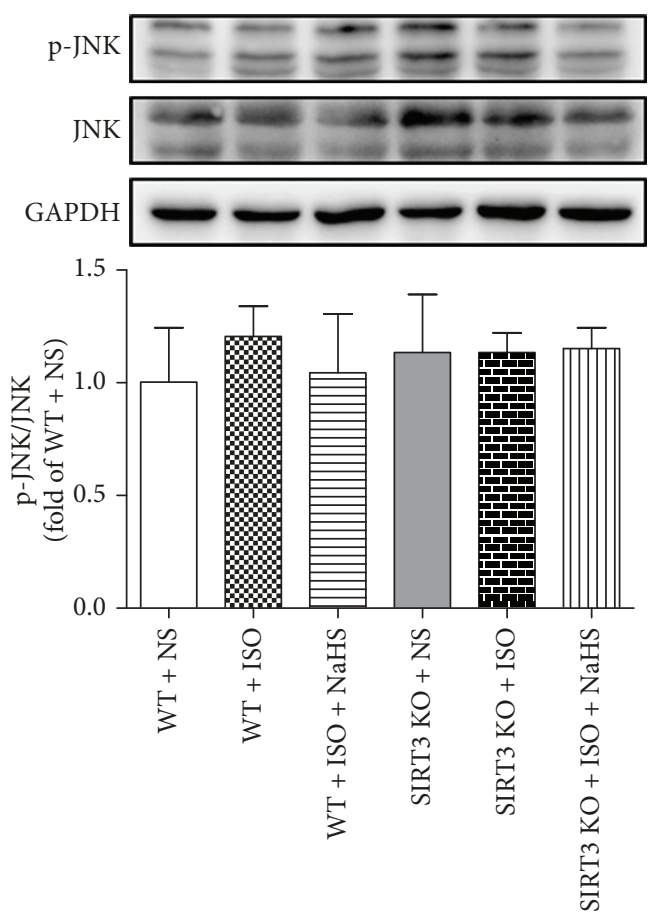

(c)

FIGURE 8: Effect of NaHS on MAPK expression and phosphorylation in WT mice and SIRT3 KO mice after ISO administration. Male 129S1/ SvImJ (WT) and SIRT3 knockout (KO) mice at 10 weeks of age were administrated with NaHS ( $50 \mu \mathrm{mol} / \mathrm{kg} / \mathrm{d})$ or normal saline (NS) once daily. After 2 weeks, the mice were given isoproterenol (ISO, $60 \mathrm{mg} / \mathrm{kg}$ ) by intraperitoneal injection followed by NaHS or NS administration once daily for another 2 weeks. (a-c) MAPK expression and phosphorylation in the myocardium of mice were measured by western blot. GAPDH was serviced as a loading control. Plots represent the mean \pm SEM; $n=6$. Statistical significance: ${ }^{*} P<0.05$ compared with WT + NS; ${ }^{\#} P<0.01$ compared with WT + ISO; ${ }^{\circledR} P<0.05$ compared with SIRT3 KO + NS.

was abolished by ERK inhibitors but not P38 inhibitors [68]. But ERK1/2 and P38 were considered as promoters of cardiac hypertrophy $[69,70]$. NaHS concentration- dependent downregulated ERK expression and inhibited the proliferation of smooth muscle cells, but not in serumfree culture cells [71]. $\mathrm{Na}_{2} \mathrm{~S}$ preadministration 7 days before 

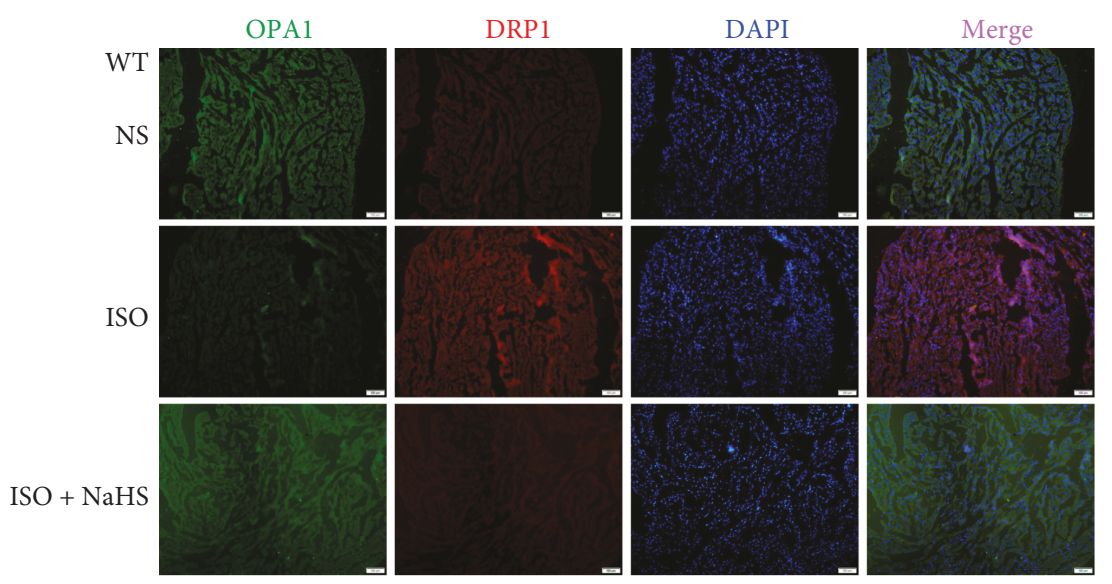

(a)
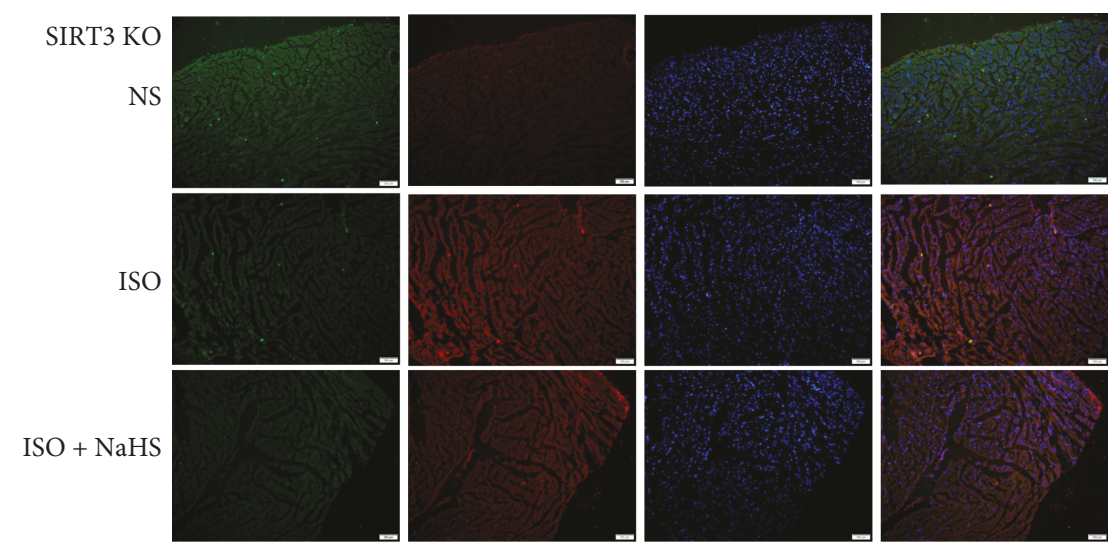

(b)

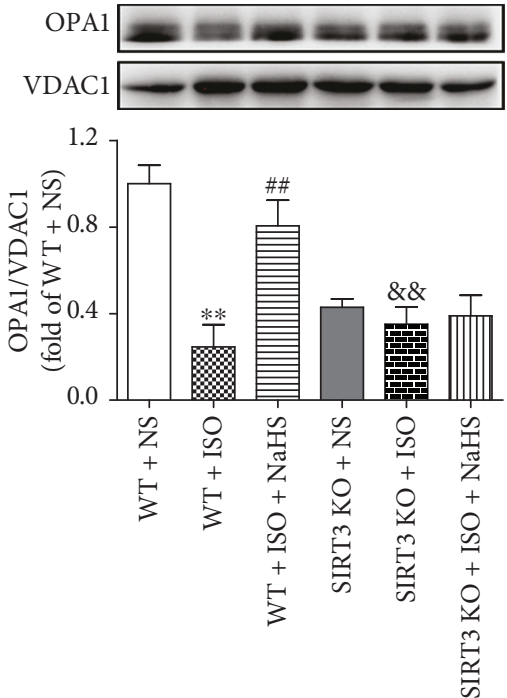

(c)

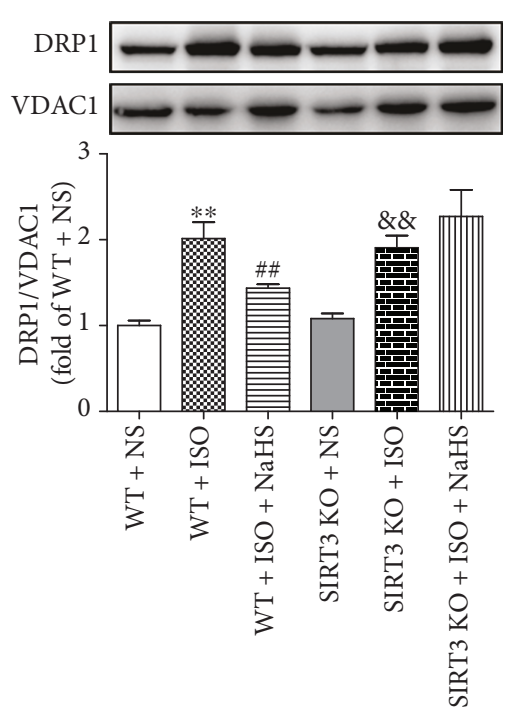

(d)

FIGURE 9: Effect of NaHS on OPA1 and DRP1 in WT mice and SIRT3 KO mice after ISO administration. Male 129S1/SvImJ (WT) and SIRT3 knockout (KO) mice at 10 weeks of age were administrated with NaHS $(50 \mu \mathrm{mol} / \mathrm{kg} / \mathrm{d})$ or normal saline (NS) once daily. After 2 weeks, the mice were given isoproterenol (ISO, $60 \mathrm{mg} / \mathrm{kg}$ ) by intraperitoneal injection followed by NaHS or NS administration once daily for another 2 weeks. (a-b) The myocardium of mice was stained with OPA1 and DRP1 followed by Alexa Fluor 488- or Cy3-conjugated IgG, respectively. Tissue sections were photographed with a fluorescence microscope. The nuclei were counterstained with DAPI (blue). Bar $=100 \mu \mathrm{m}$. (c-d) The expression of OPA1 and DRP1 in mitochondrial proteins from the myocardium of mice was measured by western blot. VDAC1 was serviced as a loading control. Plots represent the mean \pm SEM; $n=6$. Statistical significance: ${ }^{* *} P<0.01$ compared with WT + NS; \#\# $P<0.01$ compared with WT + ISO; ${ }^{\& \&} P<0.01$ compared with SIRT3 KO + NS. 
ischemia reperfusion significantly enhanced the phosphorylation of ERK to protect the heart from ischemia reperfusion injury in diabetic mice [72]. Exogenous $\mathrm{H}_{2} \mathrm{~S}$ protected $\mathrm{H} 9 \mathrm{C} 2$ cardiac cells against high glucose-induced injury and attenuated doxorubicin-induced cardiotoxicity by inhibiting the activities of the P38 or ERK1/2 pathway [73, 74]. $\mathrm{H}_{2} \mathrm{~S}$ also alleviated doxorubicin-induced cardiomyopathy through suppressing JNK activation in the hearts [75]. Moreover, $\mathrm{H}_{2} \mathrm{~S}$ failed to decrease the phosphorylation of JNK, but it was still able to attenuate the phosphorylation of P38 and ERK in $\mathrm{H}_{2} \mathrm{O}_{2}$-stimulated endothelial cells [23]. Our study discovered that exogenous NaHS administration significantly decreased the phosphorylation of ERK in hypertrophic myocardium, which was unavailable in SIRT3 deficiency mice. In other words, although $\mathrm{H}_{2} \mathrm{~S}$ plays diverse roles on MAPK signal pathway with different status, $\mathrm{H}_{2} \mathrm{~S}$-attenuated myocardial hypertrophy is, in part, mediated through blocking the ERK pathway via a SIRT3-dependent manner.

However, the detailed mechanism of the antioxidative ability of $\mathrm{H}_{2} \mathrm{~S}$ remains unknown until now. It was interesting to find that the above protective effects on myocardial hypertrophy were abolished in the SIRT3 KO mice in the present study. Our previous study also found that $\mathrm{H}_{2} \mathrm{~S}$ protected endothelial cells against oxidative stress in a SIRT3dependent manner [23]. SIRT3 regulates the deacetylation of mitochondrial proteins, and the mitochondrial proteins were highly acetylated in the SIRT3 deficiency mice, which alleviated protein activity and disordered the ATP formation, suppressed the Krebs cycle, inhibited the electron transport chain transmission, and eventually aggravated the tissue damage and resulted in oxidative stress [76]. SIRT3 is vital for attenuating myocardial ischemia reperfusion injury [77, 78], maintaining vascular biology, and suppressing atherogenesis [79]. In contrast, SIRT3 overexpression in mice hearts protected against myocardial hypertrophy and fibrosis $[80,81]$. These data indicated that SIRT3 was important in both physiology and oxidative stress-associated pathological situations [82]. Our study confirmed that NaHS attenuated myocardial hypertrophy in the WT mice, which might be related to the preventive effect on mitochondrial function and oxidative stress [83]. However, NaHS failed to attenuate IVS and LVPW thickness, cardiac indexes, cardiomyocyte area, hypertrophic gene expression, oxidative stress, and ERK phosphorylation in the SIRT3 KO mice, which might be related to the increased acetylated proteins after SIRT3 was deficient.

OPA1 regulates mitochondrial structure, respiratory regulation efficiency, respiratory chain component, and protein complex. It plays an important role in the maintenance of mitochondrial integrity and mitochondrial fusion [84, 85]. Previous studies found that the OPA1 was acetylated at lysine 926 and lysine 931 residues in SIRT3-deficient cells by mass spectrometry, so as to regulate mitochondrial dynamics during stress [86]. DRP1 is a member of the super family of protein in GTPases and is crucial for the fission of mitochondria and peroxidase in mammalian cells. It is considered to be the novel target for cardiovascular diseases [87-89]. We found that NaHS failed to enhance OPA1 expression and reduce DRP1 formation in ISO-administrated SIRT3 KO mice, which may be one of the reasons that NaHS failed to improve oxidative stress and myocardial hypertrophy after ISO administration in SIRT3 KO mice.

In conclusion, the study suggested that exogenous $\mathrm{H}_{2} \mathrm{~S}$ supplement inhibited ISO-induced cardiac hypertrophy depending on SIRT3, and the possible mechanisms might be associated with antioxidant stress. It highlighted a novel therapeutic target, SIRT3, for the protective effect of $\mathrm{H}_{2} \mathrm{~S}$ against myocardial hypertrophy.

\section{Data Availability}

The data used to support the findings of this study are available from the corresponding author upon request.

\section{Conflicts of Interest}

The authors declare that there is no conflict of interests regarding the publication of this paper.

\section{Authors' Contributions}

Jingyao Zhang, Jin Yu, and Yun Chen contributed equally to this study.

\section{Acknowledgments}

This work was supported by grants from the National Natural Science Foundation of China (81770279, 31500649), a major project of the Natural Science Research of Jiangsu Higher Education Institutions of China (18KJA310005), the project of the "Six Talent Peaks Project in Jiangsu Province" (2018-WSN-062), a project funded by the China Postdoctoral Science Foundation (2017M610342), Postgraduate Research \& Practice Innovation Program of Jiangsu Province $(1701050 \mathrm{~A})$, a research and innovation project of the Graduate Students in Jiangsu Province (KYCX18_2401, KYLX16_0979) and Nantong University (YKC16055), grants from the Natural Science Foundation of Nantong City (MS12015015, MS12015101), and the Nantong University Cooperative Innovation Program of Small Molecular Compound R\&D (NTU2016-1).

\section{References}

[1] M. A. Peterzan, C. A. Lygate, S. Neubauer, and O. J. Rider, "Metabolic remodeling in hypertrophied and failing myocardium: a review," American Journal of Physiology-Heart and Circulatory Physiology, vol. 313, no. 3, pp. H597-H616, 2017.

[2] T. Stanton and F. G. Dunn, "Hypertension, left ventricular hypertrophy, and myocardial ischemia," The Medical Clinics of North America, vol. 101, no. 1, pp. 29-41, 2017.

[3] A. M. Rababa'h, A. N. Guillory, R. Mustafa, and T. Hijjawi, "Oxidative stress and cardiac remodeling: an updated edge," Current Cardiology Reviews, vol. 14, no. 1, pp. 53-59, 2018.

[4] L. Zhao, D. Wu, M. Sang, Y. Xu, Z. Liu, and Q. Wu, "Stachydrine ameliorates isoproterenol-induced cardiac hypertrophy and fibrosis by suppressing inflammation and oxidative stress through inhibiting NF- $\mathrm{KB}$ and JAK/STAT signaling pathways 
in rats," International Immunopharmacology, vol. 48, pp. 102109, 2017.

[5] J. Lu, Y. Shen, L. J. Liu, H. Y. Qian, and C. L. Zhu, "Combining epinephrine and esmolol attenuates excessive autophagy and mitophagy in rat cardiomyocytes after cardiac arrest," Journal of Cardiovascular Pharmacology, vol. 66, no. 5, pp. 449-456, 2015.

[6] R. J. Liao, L. J. Tong, C. Huang et al., "Rescue of cardiac failing and remodelling by inhibition of protein phosphatase $1 \gamma$ is associated with suppression of the alternative splicing factormediated splicing of $\mathrm{Ca}^{2+} /$ calmodulin-dependent protein kinase $\delta$," Clinical and Experimental Pharmacology, vol. 41, no. 12, pp. 976-985, 2014.

[7] X. L. Xu, Q. Y. Zhu, C. Zhao et al., "The effect of 2,3,4',5-tetrahydroxystilbene-2-O- $\beta$-D-glucoside on pressure overloadinduced cardiac remodeling in rats and its possible mechanism," Planta Medica, vol. 80, no. 2-3, pp. 130-138, 2014.

[8] C. Chen, M. Ponnusamy, C. Liu, J. Gao, K. Wang, and P. Li, "MicroRNA as a therapeutic target in cardiac remodeling," Biomed Research International, vol. 2017, Article ID 1278436, 25 pages, 2017.

[9] S. Liu, Y. Ji, J. Yao et al., "Knockout of the prostaglandin E2receptor subtype 3 promotes eccentric cardiac hypertrophy and fibrosis in mice," Journal of Cardiovascular Pharmacology and Therapeutics, vol. 22, no. 1, pp. 71-82, 2016.

[10] G. Meng, S. Zhao, L. Xie, Y. Han, and Y. Ji, "Protein S-sulfhydration by hydrogen sulfide in cardiovascular system," British Journal of Pharmacology, vol. 175, no. 8, pp. 1146-1156, 2018.

[11] S. J. Chan and P. T. H. Wong, "Reprint of: hydrogen sulfide in stroke: protective or deleterious?," Neurochemistry International, vol. 107, pp. 78-87, 2017.

[12] J. Pichette and J. Gagnon, "Implications of hydrogen sulfide in glucose regulation: How $\mathrm{H}_{2} \mathrm{~S}$ can alter glucose homeostasis through metabolic hormones," Oxidative Medicine and Cellular Longevity, vol. 2016, Article ID 3285074, 5 pages, 2016.

[13] S. Panthi, H. J. Chung, J. Jung, and N. Y. Jeong, "Physiological importance of hydrogen sulfide: emerging potent neuroprotector and neuromodulator," Oxidative Medicine and Cellular Longevity, vol. 2016, Article ID 9049782, 11 pages, 2016.

[14] Z. Z. Xie, Y. Liu, and J. S. Bian, "Hydrogen sulfide and cellular redox homeostasis," Oxidative Medicine and Cellular Longevity, vol. 2016, Article ID 6043038, 12 pages, 2016.

[15] Y. Shen, Z. Shen, S. Luo, W. Guo, and Y. Z. Zhu, "The cardioprotective effects of hydrogen sulfide in heart diseases: from molecular mechanisms to therapeutic potential," Oxidative Medicine and Cellular Longevity, vol. 2015, Article ID 925167, 13 pages, 2015.

[16] S. Zhang, C. Pan, F. Zhou et al., "Hydrogen sulfide as a potential therapeutic target in fibrosis," Oxidative Medicine and Cellular Longevity, vol. 2015, Article ID 593407, 12 pages, 2015.

[17] G. Meng, Y. Ma, L. Xie, A. Ferro, and Y. Ji, "Emerging role of hydrogen sulfide in hypertension and related cardiovascular diseases," British Journal of Pharmacology, vol. 172, no. 23, pp. 5501-5511, 2015.

[18] S. R. Lee, B. Nilius, and J. Han, "Gaseous signaling molecules in cardiovascular function: from mechanisms to clinical translation," Reviews of Physiology Biochemistry and Pharmacology, vol. 174, pp. 81-156, 2018.
[19] Y. Xu, H. P. du, J. Li et al., "Statins upregulate cystathionine $\gamma$-lyase transcription and $\mathrm{H}_{2} \mathrm{~S}$ generation via activating Akt signaling in macrophage," Pharmacological Research, vol. 87, pp. 18-25, 2014.

[20] G. Meng, Y. Xiao, Y. Ma et al., "Hydrogen sulfide regulates Krüppel-like factor 5 transcription activity via specificity protein $1 \mathrm{~S}$-sulfhydration at Cys664 to prevent myocardial hypertrophy," Journal of the American Heart Association, vol. 5, no. 9, article e004160, 2016.

[21] G. Meng, J. Liu, S. Liu et al., "Hydrogen sulfide pretreatment improves mitochondrial function in myocardial hypertrophy via a SIRT3-dependent manner," British Journal of Pharmacology, vol. 175, no. 8, pp. 1126-1145, 2018.

[22] G. Meng, J. Zhu, Y. Xiao et al., "Hydrogen sulfide donor GYY4137 protects against myocardial fibrosis," Oxidative Medicine and Cellular Longevity, vol. 2015, Article ID 691070, 14 pages, 2015.

[23] L. Xie, H. Feng, S. Li et al., "SIRT3 mediates the antioxidant effect of hydrogen sulfide in endothelial cells," Antioxidants \& Redox Signaling, vol. 24, no. 6, pp. 329-343, 2016.

[24] L. Xie, Y. Gu, M. Wen et al., "Hydrogen sulfide induces keap1 S-sulfhydration and suppresses diabetes-accelerated atherosclerosis via NRF2 activation," Diabetes, vol. 65, no. 10, pp. 3171-3184, 2016.

[25] A. Chhabra, S. Mishra, G. Kumar et al., "Glucose-6-phosphate dehydrogenase is critical for suppression of cardiac hypertrophy by $\mathrm{H}_{2} \mathrm{~S}$," Cell Death Discovery, vol. 4, no. 1, 6 pages, 2018.

[26] V. Kesherwani, S. S. Nandi, S. K. Sharawat, H. R. Shahshahan, and P. K. Mishra, "Hydrogen sulfide mitigates homocysteinemediated pathological remodeling by inducing miR-133a in cardiomyocytes," Molecular and Cellular Biochemistry, vol. 404, no. 1-2, pp. 241-250, 2015.

[27] X. Zhou, L. Zhao, J. Mao, J. Huang, and J. Chen, "Antioxidant effects of hydrogen sulfide on left ventricular remodeling in smoking rats are mediated via PI3K/Akt-dependent activation of Nrf2," Toxicological Sciences, vol. 144, no. 1, pp. 197-203, 2015.

[28] X. Tang, X. F. Chen, H. Z. Chen, and D. P. Liu, "Mitochondrial sirtuins in cardiometabolic diseases," Clinical Science, vol. 131, no. 16, pp. 2063-2078, 2017.

[29] B. Martín-Fernández and R. Gredilla, "Mitochondria and oxidative stress in heart aging," Age, vol. 38, no. 4, pp. 225-238, 2016.

[30] J. M. Grillon, K. R. Johnson, K. Kotlo, and R. S. Danziger, "Non-histone lysine acetylated proteins in heart failure," Biochimica et Biophysica Acta (BBA) - Molecular Basis of Disease, vol. 1822, no. 4, pp. 607-614, 2012.

[31] S. S. Bharathi, Y. Zhang, A. W. Mohsen et al., "Sirtuin 3 (SIRT3) protein regulates long-chain acyl-CoA dehydrogenase by deacetylating conserved lysines near the active site," The Journal of Biological Chemistry, vol. 288, no. 47, pp. 3383733847, 2013.

[32] C. Koentges, C. Bode, and H. Bugger, "SIRT3 in cardiac physiology and disease," Frontiers in Cardiovascular Medicine, vol. 3, 2016.

[33] S. Matsushima and J. Sadoshima, "The role of sirtuins in cardiac disease," American Journal of Physiology-Heart and Circulatory Physiology, vol. 309, no. 9, pp. H1375-H1389, 2015.

[34] V. B. Pillai, S. Samant, N. R. Sundaresan et al., "Honokiol blocks and reverses cardiac hypertrophy in mice by activating 
mitochondrial Sirt3," Nature Communications, vol. 6, no. 1, p. $6656,2015$.

[35] T. Chen, J. Li, J. Liu et al., "Activation of SIRT3 by resveratrol ameliorates cardiac fibrosis and improves cardiac function via the TGF- $\beta /$ Smad3 pathway," American Journal of PhysiologyHeart and Circulatory Physiology, vol. 308, no. 5, pp. H424H434, 2015.

[36] C. F. Lee, J. D. Chavez, L. Garcia-Menendez et al., "Normalization of $\mathrm{NAD}^{+}$redox balance as a therapy for heart failure," Circulation, vol. 134, no. 12, pp. 883-894, 2016.

[37] T. Yamamoto, J. Byun, P. Zhai, Y. Ikeda, S. Oka, and J. Sadoshima, "Nicotinamide mononucleotide, an intermediate of $\mathrm{NAD}^{+}$synthesis, protects the heart from ischemia and reperfusion," PLoS One, vol. 9, no. 6, article e98972, 2014.

[38] J. Liu, T. Wang, X. Wang et al., "Development of novel $\beta$ carboline-based hydroxamate derivatives as HDAC inhibitors with DNA damage and apoptosis inducing abilities," MedChemComm, vol. 8, no. 6, pp. 1213-1219, 2017.

[39] Y. Xu, Y. Wang, G. Wang et al., "YiQiFuMai powder injection protects against ischemic stroke via inhibiting neuronal apoptosis and PKCS/Drp1-mediated excessive mitochondrial fission," Oxidative Medicine and Cellular Longevity, vol. 2017, Article ID 1832093, 17 pages, 2017.

[40] X. Ren, L. Chen, J. Xie et al., "Resveratrol ameliorates mitochondrial elongation via Drp1/Parkin/PINK1 signaling in senescent-like cardiomyocytes," Oxidative Medicine and Cellular Longevity, vol. 2017, Article ID 4175353, 20 pages, 2017.

[41] B. Wu, J. Li, H. Ni et al., "TLR4 activation promotes the progression of experimental autoimmune myocarditis to dilated cardiomyopathy by inducing mitochondrial dynamic imbalance," Oxidative Medicine and Cellular Longevity, vol. 2018, Article ID 3181278, 15 pages, 2018.

[42] C. Busquets-Cortés, X. Capó, M. Martorell, J. A. Tur, A. Sureda, and A. Pons, "Training enhances immune cells mitochondrial biosynthesis, fission, fusion, and their antioxidant capabilities synergistically with dietary docosahexaenoic supplementation," Oxidative Medicine and Cellular Longevity, vol. 2016, Article ID 8950384, 10 pages, 2016.

[43] Y. H. Yang, H. L. Fang, M. Zhao et al., "Specific $\alpha 7$ nicotinic acetylcholine receptor agonist ameliorates isoproterenolinduced cardiac remodelling in mice through TGF- $\beta 1 / \mathrm{Smad} 3$ pathway," Clinical and Experimental Pharmacology and Physiology, vol. 44, no. 12, pp. 1192-1200, 2017.

[44] P. Wang, L. Luo, Q. Shen et al., "Rosuvastatin improves myocardial hypertrophy after hemodynamic pressure overload via regulating the crosstalk of Nrf2/ARE and TGF- $\beta$ /smads pathways in rat heart," European Journal of Pharmacology, vol. 820, pp. 173-182, 2018.

[45] C. Wang, X. Nie, Y. Zhang et al., "Reactive oxygen species mediate nitric oxide production through ERK/JNK MAPK signaling in HAPI microglia after PFOS exposure," Toxicology and Applied Pharmacology, vol. 288, no. 2, pp. 143-151, 2015.

[46] X.-D. Yang, Q. Shi, J. Sun et al., “Aberrant alterations of mitochondrial factors Drp1 and Opal in the brains of scrapie experiment rodents," Journal of Molecular Neuroscience, vol. 61, no. 3, pp. 368-378, 2017.

[47] V. S. S. Gonçalves, K. R. C. Andrade, K. M. B. Carvalho, M. T. Silva, M. G. Pereira, and T. F. Galvao, "Accuracy of selfreported hypertension: a systematic review and meta-analysis," Journal of Hypertension, vol. 36, no. 5, pp. 970-978, 2018.
[48] G. Yang, L. Wu, B. Jiang et al., " $\mathrm{H}_{2} \mathrm{~S}$ as a physiologic vasorelaxant: hypertension in mice with deletion of cystathionine gamma-lyase," Science, vol. 322, no. 5901, pp. 587-590, 2008.

[49] L. Li, M. Whiteman, Y. Y. Guan et al., "Characterization of a novel, water-soluble hydrogen sulfide-releasing molecule (GYY4137): new insights into the biology of hydrogen sulfide," Circulation, vol. 117, no. 18, pp. 2351-2360, 2008.

[50] G. J. Weber, S. B. Pushpakumar, and U. Sen, "Hydrogen sulfide alleviates hypertensive kidney dysfunction through an epigenetic mechanism," American Journal of PhysiologyHeart and Circulatory Physiology, vol. 312, no. 5, pp. H874H885, 2017.

[51] K. W. Swan, B. M. Song, A. L. Chen et al., "Analysis of decreases in systemic arterial pressure and heart rate in response to the hydrogen sulfide donor sodium sulfide," American Journal of Physiology-Heart and Circulatory Physiology, vol. 313, no. 4, pp. H732-H743, 2017.

[52] C. Cuspidi, C. Sala, M. L. Muiesan, N. de Luca, G. Schillaci, and Working Group on Heart, Hypertension of the Italian Society of Hypertension., "Right ventricular hypertrophy in systemic hypertension: an updated review of clinical studies," Journal of Hypertension, vol. 31, no. 5, pp. 858-865, 2013.

[53] C. Cuspidi, M. Rescaldani, C. Sala, and G. Grassi, "Leftventricular hypertrophy and obesity: a systematic review and meta-analysis of echocardiographic studies," Journal of Hypertension, vol. 32, no. 1, pp. 16-25, 2014.

[54] T. Oka, H. Akazawa, A. T. Naito, and I. Komuro, “Angiogenesis and cardiac hypertrophy: maintenance of cardiac function and causative roles in heart failure," Circulation Research, vol. 114, no. 3, pp. 565-571, 2014.

[55] J. Huang, D. Wang, J. Zheng, X. Huang, and H. Jin, "Hydrogen sulfide attenuates cardiac hypertrophy and fibrosis induced by abdominal aortic coarctation in rats," Molecular Medicine Reports, vol. 5, no. 4, pp. 923-928, 2012.

[56] S. Y. Liu, X. C. Duan, S. Jin et al., "Hydrogen sulfide improves myocardial remodeling via downregulated angiotensin II/ AT1R pathway in renovascular hypertensive rats," American Journal of Hypertension, vol. 30, no. 1, pp. 67-74, 2017.

[57] M. Shao, C. Zhuo, R. Jiang et al., "Protective effect of hydrogen sulphide against myocardial hypertrophy in mice," Oncotarget, vol. 8, no. 14, pp. 22344-22352, 2017.

[58] P. Huang, Z. Shen, W. Yu et al., "Hydrogen sulfide inhibits high-salt diet-induced myocardial oxidative stress and myocardial hypertrophy in Dahl rats," Frontiers in Pharmacology, vol. 8, p. 128, 2017.

[59] Y. X. Shi, Y. Chen, Y. Z. Zhu et al., "Chronic sodium hydrosulfide treatment decreases medial thickening of intramyocardial coronary arterioles, interstitial fibrosis, and ROS production in spontaneously hypertensive rats," American Journal of Physiology-Heart and Circulatory Physiology, vol. 293, no. 4, pp. H2093-H2100, 2007.

[60] M. Hu, W. Zou, C. Y. Wang et al., "Hydrogen sulfide protects against chronic unpredictable mild stress-induced oxidative stress in hippocampus by upregulation of BDNF-TrKB pathway," Oxidative Medicine and Cellular Longevity, vol. 2016, Article ID 2153745, 10 pages, 2016.

[61] L. Y. Chen, Q. Chen, X. J. Zhu et al., "Diallyl trisulfide protects against ethanol-induced oxidative stress and apoptosis via a hydrogen sulfide-mediated mechanism," International Immunopharmacology, vol. 36, pp. 23-30, 2016. 
[62] L. Li, M. Li, Y. Li et al., "Exogenous $\mathrm{H}_{2} \mathrm{~S}$ contributes to recovery of ischemic post-conditioning-induced cardioprotection by decrease of ROS level via down-regulation of NF- $\kappa B$ and JAK2-STAT3 pathways in the aging cardiomyocytes," CelleBioscience, vol. 6, no. 1, p. 26, 2016.

[63] P. Huang, Z. Shen, J. Liu et al., "Hydrogen sulfide inhibits high-salt diet-induced renal oxidative stress and kidney injury in dahl rats," Oxidative Medicine and Cellular Longevity, vol. 2016, Article ID 2807490, 15 pages, 2016.

[64] Z. H. I.-H. A. I. Han, Y. Jiang, Y. Y. Duan, X. Y. Wang, Y. Huang, and T. Z. Fang, "Protective effects of hydrogen sulfide inhalation on oxidative stress in rats with cotton smoke inhalation-induced lung injury," Experimental and Therapeutic Medicine, vol. 10, no. 1, pp. 164-168, 2015.

[65] E. Dongó, I. Hornyák, Z. Benkő, and L. Kiss, “The cardioprotective potential of hydrogen sulfide in myocardial ischemia/ reperfusion injury (review)," Acta Physiologica Hungarica, vol. 98, no. 4, pp. 369-381, 2011.

[66] G. Szabó, G. Veres, T. Radovits et al., "Cardioprotective effects of hydrogen sulfide," Nitric Oxide: Biology and Chemistry, vol. 25, no. 2, pp. 201-210, 2011.

[67] P. Wang, J. X. Zhang, J. P. Gong, L. F. Li, P. L. Jin, and C. M. Ding, "Effects of hydrogen sulfide on pulmonary surfactant in rats with acute lung injury induced by lipopolysccharide," Chinese Journal of Applied Physiology, vol. 27, no. 4, pp. 485489, 2011.

[68] G. Yang, X. Sun, and R. Wang, "Hydrogen sulfide-induced apoptosis of human aorta smooth muscle cells via the activation of mitogen-activated protein kinases and caspase-3," FASEB Journal, vol. 18, no. 14, pp. 1782-1784, 2004.

[69] P. Arabacilar and M. Marber, "The case for inhibiting p38 mitogen-activated protein kinase in heart failure," Frontiers in Pharmacology, vol. 6, 2015.

[70] M. Mutlak and I. Kehat, "Extracellular signal-regulated kinases $1 / 2$ as regulators of cardiac hypertrophy," Frontiers in Pharmacology, vol. 6, 2015.

[71] J. Du, Y. Hui, Y. Cheung et al., "The possible role of hydrogen sulfide as a smooth muscle cell proliferation inhibitor in rat cultured cells," Heart and Vessels, vol. 19, no. 2, pp. 75-80, 2004.

[72] B. F. Peake, C. K. Nicholson, J. P. Lambert et al., "Hydrogen sulfide preconditions the $\mathrm{db} / \mathrm{db}$ diabetic mouse heart against ischemia-reperfusion injury by activating Nrf2 signaling in an Erk-dependent manner," American Journal of PhysiologyHeart and Circulatory Physiology, vol. 304, no. 9, pp. H1215H1224, 2013.

[73] R. Guo, J. Lin, W. Xu et al., "Hydrogen sulfide attenuates doxorubicin-induced cardiotoxicity by inhibition of the p38 MAPK pathway in H9c2 cells," International Journal of Molecular Medicine, vol. 31, no. 3, pp. 644-650, 2013.

[74] W. Xu, W. Wu, J. Chen et al., "Exogenous hydrogen sulfide protects $\mathrm{H} 9 \mathrm{c} 2$ cardiac cells against high glucose-induced injury by inhibiting the activities of the p38 MAPK and ERK1/2 pathways," International Journal of Molecular Medicine, vol. 32, no. 4, pp. 917-925, 2013.

[75] H. Zhang, A. Zhang, C. Guo et al., "S-diclofenac protects against doxorubicin-induced cardiomyopathy in mice via ameliorating cardiac gap junction remodeling," PLoS One, vol. 6, no. 10, article e26441, 2011.

[76] N. Treviño-Saldaña and G. García-Rivas, "Regulation of sirtuin-mediated protein deacetylation by cardioprotective phytochemicals," Oxidative Medicine and Cellular Longevity, vol. 2017, Article ID 1750306, 16 pages, 2017.

[77] G. A. Porter, W. R. Urciuoli, P. S. Brookes, and S. M. Nadtochiy, "SIRT3 deficiency exacerbates ischemia-reperfusion injury: implication for aged hearts," American Journal of Physiology-Heart and Circulatory Physiology, vol. 306, no. 12, pp. H1602-H1609, 2014.

[78] X. He, H. Zeng, and J. X. Chen, "Ablation of SIRT3 causes coronary microvascular dysfunction and impairs cardiac recovery post myocardial ischemia," International Journal of Cardiology, vol. 215, pp. 349-357, 2016.

[79] B. Sosnowska, M. Mazidi, P. Penson, A. Gluba-Brzózka, J. Rysz, and M. Banach, "The sirtuin family members SIRT1, SIRT3 and SIRT6: their role in vascular biology and atherogenesis," Atherosclerosis, vol. 265, pp. 275-282, 2017.

[80] N. R. Sundaresan, M. Gupta, G. Kim, S. B. Rajamohan, A. Isbatan, and M. P. Gupta, "Sirt3 blocks the cardiac hypertrophic response by augmenting Foxo3a-dependent antioxidant defense mechanisms in mice," The Journal of Clinical Investigation, vol. 119, no. 9, pp. 2758-2771, 2009.

[81] Y. Chen, H. Q. Luo, L. L. Sun et al., "Dihydromyricetin attenuates myocardial hypertrophy induced by transverse aortic constriction via oxidative stress inhibition and SIRT3 pathway enhancement," International Journal of Molecular Sciences, vol. 19, no. 9, article E2592, 2018.

[82] C. K. Singh, G. Chhabra, M. A. Ndiaye, L. M. Garcia-Peterson, N. J. Mack, and N. Ahmad, "The role of sirtuins in antioxidant and redox signaling," Antioxidants\&Redox Signaling, vol. 28, no. 8, pp. 643-661, 2018.

[83] H. D. T. F. Facundo, R. E. Brainard, F. R. . L. Caldas, and A. M. B. Lucas, "Mitochondria and cardiac hypertrophy," Advances in Experimental Medicine and Biology, vol. 982, pp. 203-226, 2017.

[84] S. Cogliati, C. Frezza, M. E. Soriano et al., "Mitochondrial cristae shape determines respiratory chain supercomplexes assembly and respiratory efficiency," Cell, vol. 155, no. 1, pp. $160-171,2013$.

[85] K. Tsushima, H. Bugger, A. R. Wende et al., "Mitochondrial reactive oxygen species in lipotoxic hearts induce posttranslational modifications of akap121, DRP1, and OPA1 that promote mitochondrial fission," Circulation Research, vol. 122, no. 1, pp. 58-73, 2018.

[86] S. A. Samant, H. J. Zhang, Z. Hong et al., "SIRT3 deacetylates and activates OPA1 to regulate mitochondrial dynamics during stress," Molecular and Cellular Biology, vol. 34, no. 5, pp. 807-819, 2014.

[87] W. W. Sharp, "Dynamin-related protein 1 as a therapeutic target in cardiac arrest," Journal of Molecular Medicine, vol. 93, no. 3, pp. 243-252, 2015.

[88] S. C. J. Helle, Q. Feng, M. J. Aebersold et al., "Mechanical force induces mitochondrial fission," Elife, vol. 6, article e30292, 2017.

[89] K. Atkins, A. Dasgupta, K. H. Chen, J. Mewburn, and S. L. Archer, "The role of Drp1 adaptor proteins MiD49 and MiD51 in mitochondrial fission: implications for human disease," Clinical Science, vol. 130, no. 21, pp. 1861-1874, 2016. 


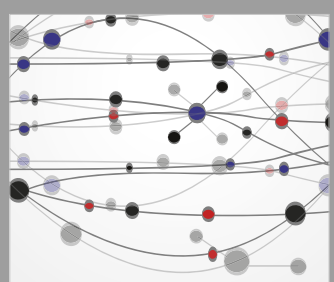

The Scientific World Journal
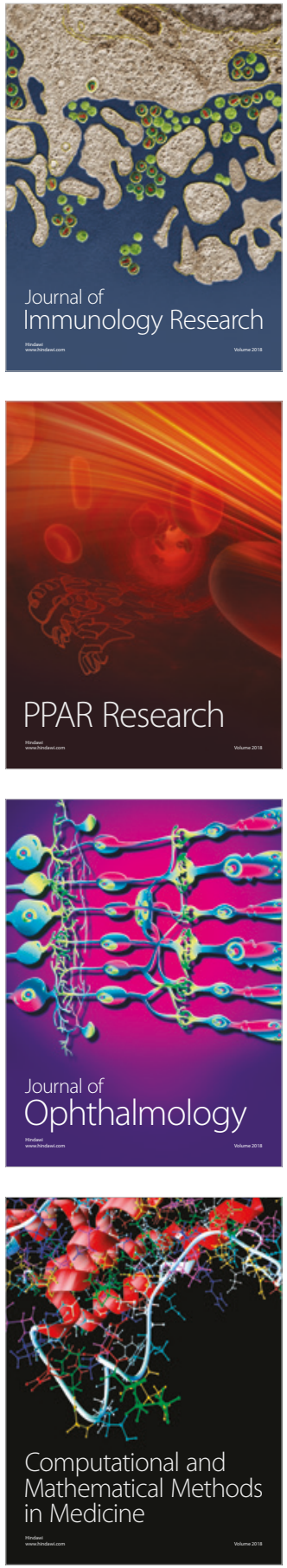

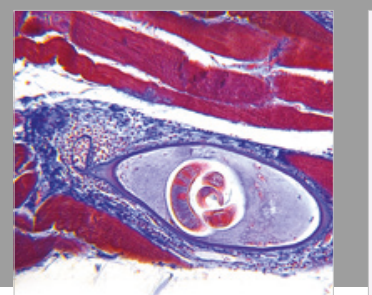

Gastroenterology Research and Practice

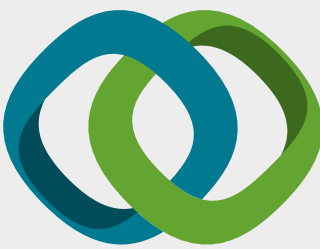

\section{Hindawi}

Submit your manuscripts at

www.hindawi.com
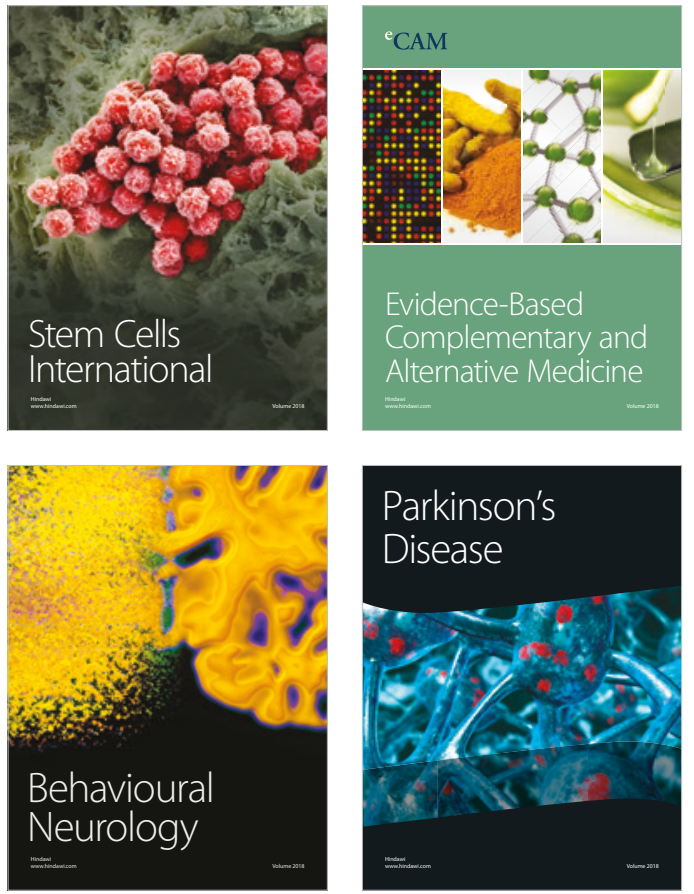

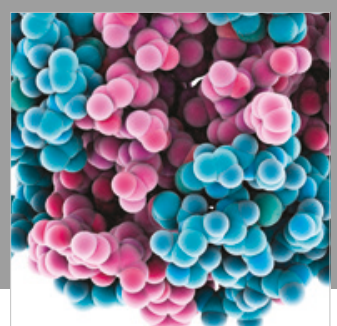

ournal of

Diabetes Research

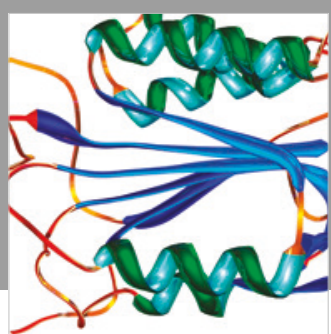

Disease Markers
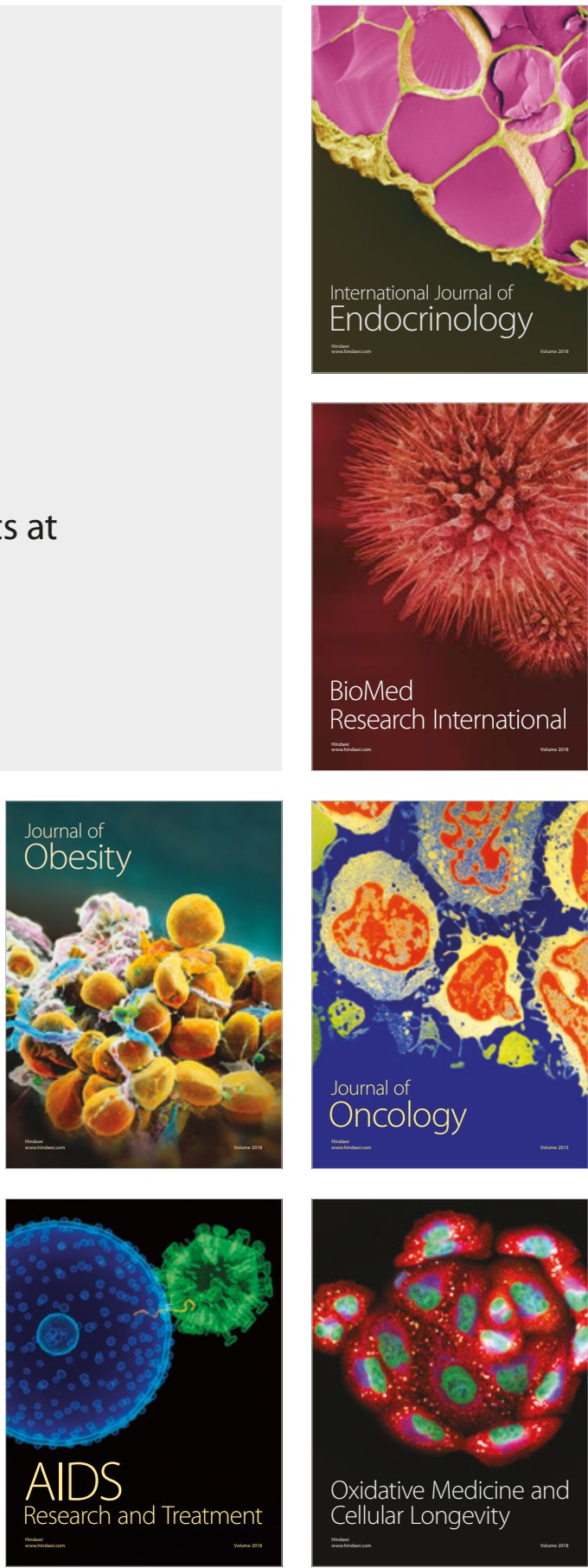